\title{
Child and Parent Perceived Determinants of Children's Inadequate Sleep Health. A Concept Mapping Study
}

\author{
Laura S. Belmon ${ }^{1,2, *(\mathbb{D})}$, Vincent Busch ${ }^{2,3, *}$, Maartje M. van Stralen ${ }^{4}$, Dominique P.M. Stijnman ${ }^{1}$, \\ Lisan M. Hidding ${ }^{1}$, Irene A. Harmsen ${ }^{3}$ and Mai J.M. Chinapaw ${ }^{1}{ }^{1}$ \\ 1 Amsterdam UMC, Vrije Universiteit Amsterdam, Department of Public and Occupational Health, \\ Amsterdam Public Health Research Institute, 1081 BT Amsterdam, The Netherlands; \\ m.chinapaw@amsterdamumc.nl \\ 2 Sarphati Amsterdam, Public Health Service (GGD), 1018 WT Amsterdam, The Netherlands \\ 3 Department of Epidemiology and Health Promotion, Section Youth, Municipal Health Service Amsterdam, \\ 1018 WT Amsterdam, The Netherlands \\ 4 Department of Health Sciences, Faculty of Science and Amsterdam Public Health Research Institute, \\ Vrije Universiteit Amsterdam, 1081 HV Amsterdam, The Netherlands \\ * Correspondence: 1.belmon@amsterdamumc.nl (L.S.B.); vbusch@ggd.amsterdam.nl (V.B.); \\ Tel.: +31-(0)20-444-5931 (L.S.B.); +31-(0)20-555-5142 (V.B.)
}

Received: 19 December 2019; Accepted: 27 February 2020; Published: 29 February 2020

check for updates

\begin{abstract}
Many children do not meet the recommendations for healthy sleep, which is concerning given the potential negative effects on children's health. To promote healthy sleep, it is crucial to understand its determinants. This concept mapping study therefore explores perspectives of children and parents on potential determinants of children's inadequate sleep. The focus lies on 9-12 year old children $(n=45)$, and their parents $(n=33)$, from low socioeconomic neighbourhoods, as these children run a higher risk of living in a sleep-disturbing environment (e.g., worries, noise). All participants generated potential reasons (i.e., ideas) for children's inadequate sleep. Next, participants sorted all ideas by relatedness and rated their importance. Subsequently, multidimensional scaling and hierarchical cluster analyses were performed to create clusters of ideas for children and parents separately. Children and parents both identified psychological (i.e., fear, affective state, stressful situation), social environmental (i.e., sleep schedule, family sleep habits), behavioural (i.e., screen behaviour, physical activity, diet), physical environmental (i.e., sleep environment such as temperature, noise, light), and physiological (i.e., physical well-being) determinants. These insights may be valuable for the development of future healthy sleep interventions.
\end{abstract}

Keywords: sleep; childhood; children; determinants; factors; concept mapping

\section{Introduction}

For children, healthy sleep is typically defined as a regular sleep rhythm consisting of approximately 9-11 hours per night [1] of good quality sleep (i.e., the combination of high sleep efficiency and a good subjective assessment of their own sleep) [2]. This nightly dose of healthy sleep is important for children's cognitive performance [3,4], academic performance [3,5-7], and their physical and mental health [5,8-10]. Unfortunately, children's average sleep duration has declined significantly in recent decades [11], while problems such as daytime sleepiness and longer sleep onset latency have become more prevalent $[12,13]$. This is especially apparent among children from lower socioeconomic (low SEP) neighbourhoods [14]. This may be ascribed to various environmental factors, such as noise nuisance caused by cramped housing or more parental stress caused by financial problems. 
Knowledge of the most relevant determinants is essential for the development of effective interventions [15]. A recent review of prospective studies [16] found evidence that spending more time on screens (e.g., TV, computer, games), having a difficult temperament, and past poor or inadequate sleep health (i.e., sleep quality or quantity) were longitudinally associated with shorter sleep duration. Another review summarized empirical evidence related to common paediatric sleep recommendations and identified having an inappropriate bedtime, not having a relaxing bedtime routine, having an irregular sleep schedule, a negative emotional environment (e.g., family stress, family conflict), and poorer emotional well-being (e.g., higher levels of internalizing symptoms) as potential determinants of children's inadequate sleep [17]. However, the perspectives of children and their parents are lacking in the current literature.

The perspectives of children and their parents could bring about new and important insights into potential determinants of inadequate sleep, which can subsequently inform intervention development. Consequently, the aim of this study is to explore the perspectives of children and parents living in low-SEP neighbourhoods on potential determinants of children's inadequate sleep health.

\section{Materials and Methods}

A participatory mixed-methods concept mapping study was conducted to assess children's and parents' perspectives on potential determinants of children's inadequate sleep health [18]. For the qualitative part of this approach, participants generated ideas about potential determinants during group brainstorm sessions, and subsequently rated these ideas according to importance. Researchers were not allowed to add or prompt additional ideas. Concept mapping is a 6-step process (see Figure 1). The first five steps are illustrated below. Step six includes the identification of perceived determinants that might be included in future healthy sleep interventions (see Discussion). Concept mapping has been used in previous studies into children's perspectives on behavioural determinants [19,20]. Additional information about the concept mapping approach can be found elsewhere [18].

\begin{tabular}{|c|c|c|c|c|c|c|c|c|}
\hline 1 & Preparation & 2 & Generation of ideas & 3 & Structuring of ideas & 4 Analyses & 5 Interpretation & Utilization \\
\hline & $\begin{array}{l}\text { Development of } \\
\text { the focus for the } \\
\text { conceptualization } \\
\text { by the research } \\
\text { team. } \\
\text { Participants and } \\
\text { recruitment. }\end{array}$ & & $\begin{array}{l}\text { Participants } \\
\text { brainstorm according } \\
\text { to the focus } \\
\text { statement: } \\
\text { Children: } \\
\text { "When I do not sleep } \\
\text { well, this can be due } \\
\text { to..." or "How come } \\
\text { you do not sleep } \\
\text { well?" } \\
\text { Parents: } \\
\text { "When a child in the } \\
\text { age of } 4-12 \text { years does } \\
\text { not sleep well, this } \\
\text { can be due to..." } \\
\text { The research team } \\
\text { creates a unique set of } \\
\text { group ideas. }\end{array}$ & - & $\begin{array}{l}\text { Participants individually } \\
\text { organize the generated } \\
\text { ideas into groups that } \\
\text { made sense to them. } \\
\text { Participants individually } \\
\text { rate the value of the } \\
\text { generated ideas, } \\
\text { according to the rating } \\
\text { statement: } \\
\text { Children: } \\
\text { "Think about your sleep, } \\
\text { how much does this } \\
\text { affect your sleep?" } \\
\text { Parents: } \\
\text { "Think about the sleep of } \\
\text { children in the age of } 4-12 \\
\text { years, how much does } \\
\text { this affect their sleep?" }\end{array}$ & $\begin{array}{l}\text { Multidimensional } \\
\text { scaling analysis. } \\
\text { Hierarchical } \\
\text { cluster analysis. } \\
\\
\text { Production of } \\
\text { concept maps. }\end{array}$ & $\begin{array}{l}\text { Interpretation of } \\
\text { the concept } \\
\text { maps by the } \\
\text { research team. }\end{array}$ & $\begin{array}{l}\text { Identification of } \\
\text { relevant child- } \\
\text { and parent } \\
\text { perceived } \\
\text { determinants for } \\
\text { promoting } \\
\text { healthy children's } \\
\text { sleep behaviour } \\
\text { via future } \\
\text { preventive } \\
\text { interventions. }\end{array}$ \\
\hline
\end{tabular}

Figure 1. The 6-step concept mapping process.

\subsection{Preparation (Step 1)}

The preparation phase included providing focus for the conceptualization, followed by identifying and recruiting participants.

\subsubsection{Providing Focus for the Conceptualization}

The first step was the creation of a 'focus statement' and 'rating statement': a main question or statement that gives a specific instruction for the session [18]. The purpose of the focus statement is to 
elicit ideas about the topic of interest, whereas the rating statement provides comparative ratings of importance for the generated ideas (see Figure 1).

The comprehensiveness of the statements and the feasibility of the sorting and rating task were tested in a pilot study. For this, two pilot sessions were conducted with parents (9 and 6 parents, respectively) and two with children (12 and 26 children, respectively), and changes were made to clarify the focus- and rating statements.

\subsubsection{Participants and Recruitment}

Children and parents were recruited through schools and thereby grouped based on school level and availability. The health advisors of the Public Health Service of Amsterdam brought the researchers in contact with primary schools in socioeconomically disadvantaged neighbourhoods, based on the postal code of the neighbourhood [21]. Four out of 23 invited primary schools participated. When schools were willing to participate, they were asked to distribute information letters to children aged 9-12 years old and parents with at least one child in the age range 4-12 years. The age range of the children (i.e., 9-12 years) was chosen because the tasks within the study were considered conceptually too difficult for children younger than 9 years old [22]. Participating children and at least one parent/caregiver provided informed consent. Schools were offered a lecture about healthy sleep as an incentive for participation, while children received a small present and parents a gift card with a value of 10 euros. The VU University Medical Ethical Committee approved the study protocol and concluded that it does not fall within the scope of the Medical Research Involving Human Subjects Act (study protocol 2017.013).

\subsection{Generation of Ideas (Step 2)}

At each primary school, two concept mapping sessions (1 to 1.5 hours) were organized per subgroup of children or parents, with approximately one week between sessions. The sessions were facilitated by one researcher (L.S.B.) and assisted by a second researcher (M.M.v.S, V.B., I.A.H., E.M.R., E.E.V., A.W., R.P. or L.B.). Each first session consisted of generating ideas in a brainstorm session. In each session, participants were first given a 'warm-up question' to stimulate understanding of the concept: "What is inadequate sleep for you / for children?". Following this, they were encouraged to brainstorm individually about the focus statement (see Figure 1) and write down as many ideas as possible. Subsequently, everyone shared their ideas, one by one, with the rest of the group until none were left unmentioned, resulting in a complete list of original ideas per subgroup. During the first session, participants also completed a short questionnaire asking them about age, gender, education level (parents), and perceived cultural group (parents) or country of birth (children). Parents' education categories were defined as 1) low, i.e., highest education level is primary or secondary school education or no education at all;2) medium, i.e., highest education is secondary vocational education; and 3) high, i.e., highest education is higher professional education or scientific education. After each brainstorm session, ideas that were conceptually the same were merged, resulting in a set of unique ideas that were printed on cards for the second session. One researcher (L.S.B.) suggested the adaptations, which were checked by a second researcher (I.A.H.). In case of disagreement, a third researcher (V.B. or M.M.v.S.) was consulted.

\subsection{Structuring Ideas (Step 3)}

The second session consisted of structuring ideas. Firstly, participants individually sorted (i.e., clustered) all ideas by relatedness. The rules for this task were; 1 ) create a minimum of three and a maximum of 10 piles; 2 ) all cards (i.e., ideas) need to be placed on a pile; 3 ) a pile cannot consist of a single card (i.e., one idea); and 4) there cannot be a miscellaneous pile $[18,19]$. The last step of the sorting task was to name their piles of ideas. The name of each pile had to represent the relatedness between ideas. Secondly, they individually rated all ideas according to the rating statement: "Think about your sleep, how much does this affect your sleep? / Think about the sleep of a child in the age of 4-12 years, 
how much does this affect their sleep?" on a Likert scale: (1) 'does not affect at all' represented by a rested emoticon; (2) hardly affects; (3) affects a little; (4) affects a lot; (5) 'affects a whole lot' represented by a very tired emoticon [18].

\subsection{Analyses (Step 4)}

The software programme Ariadne [23] was used for the data analyses; multidimensional scaling, and hierarchical cluster analyses per subgroup [18]. We created a 'two-dimensional point map' on which each point represents an individual idea, with a specific 'distance' to the other ideas. Points that lie close to each other on the map represent ideas that were grouped together more often by participants. The table of similarities (or similarity matrix) structures the information of each participant about their perception of the relationship between ideas (i.e., the sorting task).

\subsection{Interpretation (Step 5)}

Two researchers (L.S.B. and D.P.M.S.) independently determined the optimal number of clusters for each subgroup using the divisive method and 'hierarchical cluster tree'. For this method, all ideas start off in a single cluster. Based on the individual clustering of participants, the programme subsequently suggests how the ideas can be optimally arranged into clusters when choosing two, three, four, or more clusters. The underlying ideas in each cluster were interpreted incrementally and critically reviewed until each idea was in a cluster with other ideas that reflected a similar concept [18]. Potential conflicts were resolved by a third researcher (V.B.). Some ideas were moved to another cluster or a new cluster was created when this made more sense conceptually. These decisions can be found in Appendix A (Figures A1-A10) and B (Tables A1-A10). This process continued until consensus was reached on the number and meaning of the clusters per subgroup. After this, the clusters were named based on participants' input. One concept map was created per subgroup. For the final concept maps see Appendix A.

Clusters that represented multiple topics (i.e., perceived determinants) were split up. The original ideas were merged into main ideas for children and parents separately (see Appendix B). The average importance rating of each perceived determinant was calculated based on the average importance ratings of the underlying main ideas, and the average importance rating of each main idea was based on the average importance ratings of the underlying original ideas. An average 'overall importance rating' for all perceived determinants and main ideas was calculated by combining the mean rating of all participants across all groups, for children and parents separately. This created a clear overview of the importance of the perceived determinants and main ideas across all subgroups. An average rating of $\geq 3.00$ was considered as important. Ratings between 2.95 and 2.99 were rounded to 2.9.

\section{Results}

\subsection{Participants}

The education level of the participating parents was mainly medium (42.4\%) and high (42.4\%). Six groups of children ( $N=5$ to 9$)$ and four groups of parents ( $N=7$ to 10$)$ were formed. Table 1 presents the sample characteristics. 
Table 1. Sample characteristics.

\begin{tabular}{|c|c|c|}
\hline \multicolumn{3}{|c|}{ Characteristics } \\
\hline \multicolumn{3}{|l|}{ Children $(N=45)$} \\
\hline & Age, years (M, SD) & $10.2(1.1)$ \\
\hline & Female (\%) & 62.2 \\
\hline & Born in the Netherlands (\%) & 88.9 \\
\hline \multicolumn{3}{|l|}{ Parents $(N=33)$} \\
\hline & Age, years (M, SD) & $40.4(7.9)$ \\
\hline & Female $(\%)$ & 90.9 \\
\hline & Education level (\%) & \\
\hline & Low & 9.1 \\
\hline & Medium & 42.4 \\
\hline & High & 42.4 \\
\hline & Unknown & 6.1 \\
\hline & Perceived cultural group (\%) & \\
\hline & Dutch & 36.4 \\
\hline & Turkish & 15.2 \\
\hline & Moroccan & 6.1 \\
\hline & Ghanaian & 3.0 \\
\hline & Other & 12.1 \\
\hline & Two or more groups & 27.3 \\
\hline
\end{tabular}

$N=$ number of participants; $\mathrm{M}=$ Mean; $\mathrm{SD}=$ Standard deviation.

\subsection{Concept Maps}

Children generated 30 to 58 ideas per group and parents 32 to 58 ideas. Some ideas generated in the first session were perceived as unclear or difficult in the subsequent session. In this case, the idea was excluded from sorting and rating (e.g., children in group 1 eventually discarded the idea 'dancing in my bedroom at night' and group 2 did so with 'sleepwalking'). Two of the youngest children in group 1 experienced the second session as difficult and their clustering and ratings were therefore excluded from the analyses. The final number of clusters defined by the researchers ranged from four to six, for both children and parents. As the majority of these clusters represented multiple perceived determinants, we separated them to provide a clear overview of the different perceived determinants and their mean ratings. Table 2 presents children's perceived determinants and the underlying ideas, categorized in five determinant domains: psychological, physiological, physical environmental, social environmental, and behavioural. Table 3 presents parents' perceived determinants. In both tables, the determinants and underlying ideas are sorted from high to low importance. 
Table 2. Mean importance ratings ${ }^{1}$ for the child-perceived determinants related to children's inadequate sleep.

\begin{tabular}{|c|c|c|c|c|c|c|c|c|c|}
\hline \multirow{2}{*}{ Perceived Determinants } & \multirow{2}{*}{ Main Ideas (Merged) } & \multirow{2}{*}{ Examples of Underlying Original Ideas } & \multicolumn{6}{|c|}{ Mean Rating per Child Group ${ }^{2}$} & \multirow{2}{*}{ Mean $^{3}$} \\
\hline & & & 1 & 2 & $3 A$ & $3 B$ & $4 A$ & $4 B$ & \\
\hline \multicolumn{10}{|l|}{ Psychological determinants } \\
\hline Fear & & & & & & & & & 2.9 \\
\hline & Recent scary event & $\begin{array}{l}\text { 'In bed, thinking about something scary that I } \\
\text { experienced' }\end{array}$ & N.A. & 3.6 & N.A. & N.A. & 3.1 & 3.3 & 3.3 \\
\hline & Scary thoughts & 'Having scary thoughts when I am in bed' & 3.3 & 3.6 & 2.9 & N.A. & N.A. & N.A. & 3.3 \\
\hline & Nightmares & 'Having a nightmare' & 3.1 & 3.2 & 3.2 & 2.8 & 3.0 & 3.2 & 3.1 \\
\hline & $\begin{array}{l}\text { Watch/read something } \\
\text { scary }\end{array}$ & $\begin{array}{l}\text { 'Having seen a scary movie', 'Reading a moving } \\
\text { story before I go to sleep' }\end{array}$ & 2.7 & 3.0 & N.A. & 2.6 & 3.1 & 2.7 & 2.8 \\
\hline & $\begin{array}{l}\text { Scared by something in } \\
\text { the bedroom }\end{array}$ & 'When I see scary shadows in my bedroom' & 1.4 & 2.2 & 3.4 & N.A. & N.A. & 3.3 & 2.6 \\
\hline & Being afraid & 'Being afraid when I am in bed' & 2.4 & N.A. & 2.8 & 2.4 & 2.1 & 3.2 & 2.6 \\
\hline & Scary sounds & $\begin{array}{l}\text { 'Hearing weird or scary sounds during } \\
\text { the night' }\end{array}$ & N.A. & N.A. & 2.6 & 2.4 & N.A. & N.A. & 2.5 \\
\hline \multirow[t]{11}{*}{ Affective state } & & & & & & & & & 2.6 \\
\hline & Many thoughts & 'Thinking and having many thoughts' & N.A. & N.A. & 3.8 & 4.3 & N.A. & 2.8 & 3.6 \\
\hline & $\begin{array}{l}\text { Upcoming stressful } \\
\text { event }\end{array}$ & $\begin{array}{l}\text { 'Being nervous for something that is going to } \\
\text { happen' }\end{array}$ & 3.3 & 3.0 & N.A. & 2.9 & 3.5 & 2.6 & 3.1 \\
\hline & Excitement & $\begin{array}{l}\text { 'Looking forward to something that will happen } \\
\text { the next day' }\end{array}$ & 2.6 & 3.0 & 3.0 & 3.1 & 3.3 & 2.8 & 2.9 \\
\hline & Negative affective state & 'Feeling sad', 'Being angry', 'Being irritated' & 2.4 & 2.9 & 2.8 & 2.5 & 3.0 & 3.3 & 2.8 \\
\hline & Reluctant to go to sleep & 'Not feeling like going to sleep' & 2.4 & N.A. & 2.7 & 2.4 & 3.0 & 3.6 & 2.8 \\
\hline & Recent stressful event & $\begin{array}{l}\text { 'Continuing to think about a bothersome event } \\
\text { that happened that day' }\end{array}$ & 2.3 & 2.5 & 3.0 & 2.5 & 2.2 & 2.9 & 2.6 \\
\hline & $\begin{array}{l}\text { Stressful family } \\
\text { situation }\end{array}$ & 'A fight between my parents when I am in bed' & N.A. & N.A. & N.A. & 2.2 & 3.4 & 1.7 & 2.4 \\
\hline & Feeling unsafe & $\begin{array}{l}\text { 'Not feeling comfortable because of people } \\
\text { screaming outside' }\end{array}$ & N.A. & N.A. & N.A. & 2.3 & 2.2 & 2.1 & 2.2 \\
\hline & Fear of missing out & $\begin{array}{l}\text { 'When my brother/sister is allowed to watch } \\
\text { something (TV, film) and I am not' }\end{array}$ & N.A. & N.A. & 2.0 & N.A. & N.A. & N.A. & 2.0 \\
\hline & $\begin{array}{l}\text { Lacks attention from } \\
\text { parents }\end{array}$ & $\begin{array}{l}\text { 'When my parents do not pay attention to me } \\
\text { because they are busy with my brother or sister' }\end{array}$ & N.A. & N.A. & 2.0 & N.A. & N.A. & N.A. & 2.0 \\
\hline
\end{tabular}


Table 2. Cont.

\begin{tabular}{|c|c|c|c|c|c|c|c|c|c|}
\hline \multirow{2}{*}{ Perceived Determinants } & \multirow{2}{*}{ Main Ideas (Merged) } & \multirow{2}{*}{ Examples of Underlying Original Ideas } & \multicolumn{6}{|c|}{ Mean Rating per Child Group ${ }^{2}$} & \multirow{2}{*}{ Mean $^{3}$} \\
\hline & & & 1 & 2 & $3 A$ & $3 B$ & $4 A$ & $4 B$ & \\
\hline \\
\hline \multirow[t]{5}{*}{ Discomfort } & & & & & & & & & 2.8 \\
\hline & Illness & 'Being ill', 'Having a blocked nose due to a cold' & 3.1 & 3.4 & 2.9 & 3.5 & 3.9 & 3.2 & 3.3 \\
\hline & Pain & 'Feeling pain' & 2.9 & 3.0 & N.A. & 2.5 & 3.6 & 2.2 & 2.8 \\
\hline & Needing to pee & 'Needing to pee when I am already in bed' & 2.8 & N.A. & N.A. & 2.6 & 2.7 & 2.4 & 2.6 \\
\hline & $\begin{array}{l}\text { Unhealthy dietary } \\
\text { behaviour }\end{array}$ & $\begin{array}{l}\text { 'Having had too much to eat', 'Late dinner', } \\
\text { 'Feeling hungry' }\end{array}$ & N.A. & N.A. & N.A. & 2.4 & 2.7 & 2.6 & 2.6 \\
\hline \multicolumn{10}{|c|}{ Physical environmental determinants } \\
\hline \multirow[t]{11}{*}{ Sleep environment } & & & & & & & & & 2.7 \\
\hline & $\begin{array}{l}\text { Not the right } \\
\text { temperature }\end{array}$ & 'Feeling too hot or too cold when I am in bed' & 3.8 & N.A. & 3.0 & 2.8 & 3.6 & 2.9 & 3.2 \\
\hline & $\begin{array}{l}\text { Unable to lie down } \\
\text { comfortably }\end{array}$ & 'Not able to lie down comfortably in my bed' & 3.8 & N.A. & 3.2 & 2.4 & N.A. & 3.2 & 3.1 \\
\hline & Noise outside & $\begin{array}{l}\text { 'Noise from the neighbours, e.g., yelling or } \\
\text { music' }\end{array}$ & 3.0 & 3.3 & N.A. & 2.4 & 2.9 & 3.1 & 2.9 \\
\hline & $\begin{array}{l}\text { Uncomfortable } \\
\text { sleeping materials }\end{array}$ & $\begin{array}{l}\text { 'Having no comfortable pillow', 'Wearing } \\
\text { uncomfortable pyjamas' }\end{array}$ & 2.9 & N.A. & 3.2 & N.A. & N.A. & 2.7 & 2.9 \\
\hline & Uncomfortable bed & 'Sleeping on an uncomfortable mattress' & N.A. & N.A. & N.A. & N.A. & N.A. & 2.9 & 2.9 \\
\hline & Too much light & 'Too much light in my bedroom' & 2.9 & 3.0 & N.A. & 2.4 & N.A. & 2.8 & 2.8 \\
\hline & Noise inside & $\begin{array}{l}\text { 'When the sound of the TV in our home is too } \\
\text { loud' }\end{array}$ & 2.8 & 2.2 & 2.5 & 2.4 & 2.9 & 2.59 & 2.6 \\
\hline & $\begin{array}{l}\text { Distractions in the } \\
\text { bedroom }\end{array}$ & $\begin{array}{l}\text { 'Pets that wake me up', 'Noise from a brother or } \\
\text { sister with whom I share the same room' }\end{array}$ & 2.4 & 2.4 & 2.1 & 2.0 & 2.5 & 2.2 & 2.3 \\
\hline & $\begin{array}{l}\text { Unfavourable sleeping } \\
\text { place }\end{array}$ & $\begin{array}{l}\text { 'Not sleeping at my favourite sleeping place in } \\
\text { the bunk bed' }\end{array}$ & 2.1 & N.A. & N.A. & N.A. & N.A. & N.A. & 2.1 \\
\hline & Too dark & 'A bedroom that is too dark' & N.A. & 1.8 & N.A. & N.A. & N.A. & N.A. & 1.8 \\
\hline
\end{tabular}


Table 2. Cont

\begin{tabular}{|c|c|c|c|c|c|c|c|c|c|}
\hline \multirow{2}{*}{ Perceived Determinants } & \multirow{2}{*}{ Main Ideas (Merged) } & \multirow{2}{*}{ Examples of Underlying Original Ideas } & \multicolumn{6}{|c|}{ Mean Rating per Child Group ${ }^{2}$} & \multirow{2}{*}{ Mean ${ }^{3}$} \\
\hline & & & 1 & 2 & $3 A$ & $3 B$ & $4 A$ & $4 B$ & \\
\hline \multicolumn{10}{|c|}{ Social environmental determinants } \\
\hline Sleep schedule & 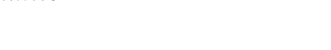 & & & & & & & & 2.6 \\
\hline & Going to bed too early & $\begin{array}{l}\text { 'Going to bed too early and not being tired } \\
\text { enough to fall asleep' }\end{array}$ & 2.8 & N.A. & 3.2 & 3.6 & 3.3 & N.A. & 3.2 \\
\hline & $\begin{array}{l}\text { No consistent sleep } \\
\text { schedule }\end{array}$ & 'Not going to bed at the same time every night' & N.A. & N.A. & 2.6 & 2.0 & 1.9 & 2.2 & 2.2 \\
\hline & Daytime nap & 'Sleeping at daytime' & N.A. & N.A. & N.A. & N.A. & 2.7 & 2.0 & 2.4 \\
\hline \multicolumn{10}{|l|}{ Behavioural determinants } \\
\hline \multirow[t]{5}{*}{ Energy } & & & & & & & & & 2.4 \\
\hline & Not being tired & 'Not being tired when I go to bed' & 3.9 & N.A. & N.A. & N.A. & 3.1 & N.A. & 3.5 \\
\hline & $\begin{array}{l}\text { Inadequate amount of } \\
\text { daytime PA }\end{array}$ & $\begin{array}{l}\text { 'Having had too little exercise during the day } \\
\text { and therefore too much energy in the evening' }\end{array}$ & 2.1 & N.A. & N.A. & 2.5 & N.A. & N.A. & 2.3 \\
\hline & $\begin{array}{l}\text { Excessive daytime } \\
\text { stimulation }\end{array}$ & 'Being too tired because I did a lot' & N.A. & N.A. & N.A. & 1.9 & N.A. & 2.22 & 2.1 \\
\hline & Evening PA & 'Doing sports late in the evening' & 1.5 & N.A. & 2.4 & N.A. & 1.9 & N.A. & 1.9 \\
\hline \multirow[t]{4}{*}{ Screen behaviour } & & & & & & & & & 1.9 \\
\hline & $\begin{array}{l}\text { Screen use around } \\
\text { bedtime }\end{array}$ & 'Using a phone or tablet before bedtime' & 2.5 & 2.0 & N.A. & 2.1 & 1.9 & 1.9 & 2.1 \\
\hline & $\begin{array}{l}\text { Social media use } \\
\text { around bedtime }\end{array}$ & $\begin{array}{l}\text { 'Messages I receive in the evening via the group } \\
\text { chat on my phone' }\end{array}$ & 1.7 & 2.0 & N.A. & N.A. & N.A. & N.A. & 1.9 \\
\hline & $\begin{array}{l}\text { Playing activating } \\
\text { games before bedtime }\end{array}$ & $\begin{array}{l}\text { 'Playing computer games right before going to } \\
\text { sleep' }\end{array}$ & 1.4 & N.A. & N.A. & 2.0 & N.A. & N.A. & 1.7 \\
\hline
\end{tabular}

N.A. = Not applicable, means the idea was not mentioned in this group of children; bold values indicate the determinant or idea was perceived as important i.e., $\geq 3.00 ;$ cursive values indicate the overall mean rating per perceived determinant. PA = Physical activity. ${ }^{1}$ The mean importance rating is based on the question: 'Think about your sleep, how much does this affect your sleep?' answered on a 5-point Likert scale from 'does not affect at all $=1$ ' to 'affects a whole $1 \operatorname{lot}^{\prime}=5^{\prime}$. ${ }^{2}$ Groups of children per school (i.e., schools $1-4$ ). At schools 3 and 4 , there were two groups of children, represented by A and B. ${ }^{3}$ Mean importance rating of all groups of children. 
Table 3. Mean importance ratings ${ }^{1}$ for the parent-perceived determinants related to children's inadequate sleep.

\begin{tabular}{|c|c|c|c|c|c|c|c|}
\hline \multirow{2}{*}{ Perceived Determinants } & \multirow{2}{*}{ Main Ideas (Merged) } & \multirow{2}{*}{ Examples of Underlying Original Ideas } & \multicolumn{4}{|c|}{ Mean Rating per Parent Group ${ }^{2}$} & \multirow[t]{2}{*}{ Mean $^{3}$} \\
\hline & & & 1 & 2 & 3 & 4 & \\
\hline \multicolumn{8}{|l|}{ Physiological determinants } \\
\hline \multirow{4}{*}{ Physical well-being } & & & & & & & 3.9 \\
\hline & Illness & 'Being ill' & 4.1 & 4.2 & 4.2 & 3.5 & 4.0 \\
\hline & Pain & 'Feeling pain' & N.A. & N.A. & 4.2 & N.A. & 4.2 \\
\hline & Sleep problem & 'Sleep walking', 'Wetting the bed' & 3.0 & N.A. & N.A. & 4.0 & 3.5 \\
\hline \multirow{8}{*}{$\begin{array}{l}\text { Psychological determinants } \\
\text { Stressful situation }\end{array}$} & & & & & & & \\
\hline & & & & & & & 3.8 \\
\hline & Feeling unsafe & $\begin{array}{l}\text { 'Not feeling safe at home, in the classroom or outside on } \\
\text { the streets' }\end{array}$ & N.A. & N.A. & 4.1 & 4.7 & 4.4 \\
\hline & Parental relationship problems & $\begin{array}{l}\text { 'Negative tension or disagreement within the family', } \\
\text { 'Parents going through a divorce' }\end{array}$ & 3.4 & 3.8 & 4.5 & 4.4 & 4.0 \\
\hline & Being bullied & & 3.4 & 3.8 & 4.2 & 4.7 & 4.0 \\
\hline & Insecurity about themselves & 'Feeling insecure about themselves' & 4.0 & N.A. & N.A. & N.A. & 4.0 \\
\hline & Parental stress & 'Parental stress (rushing) that is transferred to the child' & 3.9 & N.A. & 3.1 & 4.3 & 3.8 \\
\hline & Financial family problems & $\begin{array}{l}\text { 'Financial problems at home, meaning the parent is } \\
\text { unable to buy everything for the child' }\end{array}$ & N.A. & 2.6 & N.A. & N.A. & 2.6 \\
\hline \multirow[t]{10}{*}{ Affective state } & & & & & & & 3.6 \\
\hline & Unpleasant dreams & $\begin{array}{l}\text { 'Nightmares, 'Dreams that keep children awake or wake } \\
\text { them and cause restless sleep' }\end{array}$ & N.A. & N.A. & 3.3 & 4.5 & 3.9 \\
\hline & Upcoming stressful event & 'A stressful event coming up for the child the next day' & 4.0 & 3.8 & 3.6 & 3.5 & 3.7 \\
\hline & Being afraid & 'Being afraid when lying in bed' & N.A. & 3.6 & 3.1 & 4.5 & 3.7 \\
\hline & Many thoughts & 'Having many thoughts' & N.A. & N.A. & 3.3 & 4.2 & 3.7 \\
\hline & Recent stressful event & $\begin{array}{l}\text { 'Continuing to think about something that happened } \\
\text { that day' }\end{array}$ & 3.9 & 2.9 & 3.6 & 4.3 & 3.7 \\
\hline & Excitement & $\begin{array}{l}\text { 'Excitement, happy feelings for something that is going } \\
\text { to happen the next day' }\end{array}$ & 3.6 & 3.6 & N.A. & 3.2 & 3.4 \\
\hline & Fear of missing out & $\begin{array}{l}\text { 'Not willing to miss something and therefore not willing } \\
\text { to go to sleep' }\end{array}$ & N.A. & 3.9 & 3.1 & 3.2 & 3.4 \\
\hline & Worrying & $\begin{array}{l}\text { 'Worrying about something and not being able to share } \\
\text { this' }\end{array}$ & 3.6 & 2.9 & 3.7 & N.A. & 3.4 \\
\hline & Reluctant to go to sleep & 'Not feeling like going to sleep' & 3.0 & N.A. & N.A. & 3.3 & 3.2 \\
\hline
\end{tabular}


Table 3. Cont.

\begin{tabular}{|c|c|c|c|c|c|c|c|}
\hline \multirow{2}{*}{ Perceived Determinants } & \multirow{2}{*}{ Main Ideas (Merged) } & \multirow{2}{*}{ Examples of Underlying Original Ideas } & \multicolumn{4}{|c|}{ Mean Rating per Parent Group ${ }^{2}$} & \multirow[t]{2}{*}{ Mean $^{3}$} \\
\hline & & & 1 & 2 & 3 & 4 & \\
\hline \multicolumn{8}{|l|}{ Behavioural determinants } \\
\hline \multirow[t]{5}{*}{ Energy } & & & & & & & 3.5 \\
\hline & Being too energetic & $\begin{array}{l}\text { 'Not being tired when going to bed', 'Having too much } \\
\text { energy from his/herself' }\end{array}$ & 3.9 & N.A. & N.A. & 3.8 & 3.8 \\
\hline & Excessive daytime stimulation & $\begin{array}{l}\text { 'A busy day with excessive stimulation due to too many } \\
\text { activities' }\end{array}$ & N.A. & N.A. & 3.4 & 4.0 & 3.7 \\
\hline & Inadequate daytime stimulation & $\begin{array}{l}\text { 'A boring day with inadequate stimulation due to lack of } \\
\text { activities' }\end{array}$ & 3.6 & N.A. & 3.1 & 3.2 & 3.3 \\
\hline & Being too tired & 'Being too tired when going to bed' & 3.3 & N.A. & 3.6 & 2.8 & 3.2 \\
\hline \multirow[t]{5}{*}{ Activating activities } & & & & & & & 3.4 \\
\hline & Watching something scary & 'Watching a scary movie', 'Watching the news' & 3.4 & 4.0 & 3.6 & 3.8 & 3.7 \\
\hline & $\begin{array}{l}\text { Play with activating toys before } \\
\text { bedtime }\end{array}$ & $\begin{array}{l}\text { 'Playing with toys with a lot of light and noise right } \\
\text { before bedtime' }\end{array}$ & N.A. & 3.1 & 4.4 & N.A. & 3.8 \\
\hline & Screen use before bedtime & $\begin{array}{l}\text { 'Using the computer or other screen (phone, tablet, game } \\
\text { computer, TV) right before going to sleep' }\end{array}$ & 3.4 & 3.3 & 3.7 & 3.3 & 3.4 \\
\hline & Excessive daytime screen use & $\begin{array}{l}\text { 'Using screens (phone, tablet, game computer, TV) a lot } \\
\text { during the day' }\end{array}$ & N.A. & N.A. & N.A. & 2.7 & 2.7 \\
\hline \multirow[t]{3}{*}{ Physical activity } & & & & & & & 3.3 \\
\hline & $\begin{array}{l}\text { Inadequate amount of daytime } \\
\text { PA }\end{array}$ & $\begin{array}{l}\text { 'Inadequate amount of physical activity during the day } \\
\text { and therefore not being tired' }\end{array}$ & N.A. & 3.6 & N.A. & 3.2 & 3.4 \\
\hline & $\begin{array}{l}\text { Inadequate time outside at } \\
\text { daytime }\end{array}$ & $\begin{array}{l}\text { 'Not having played outside at daytime', 'Spending too } \\
\text { little time outside in the fresh air' }\end{array}$ & 3.0 & N.A. & N.A. & 3.3 & 3.2 \\
\hline \multirow[t]{6}{*}{ Diet } & & & & & & & 3.1 \\
\hline & Unhealthy diet & $\begin{array}{l}\text { 'Eating something sugary before bedtime', 'Unhealthy } \\
\text { diet during the day' }\end{array}$ & 3.4 & 3.6 & N.A. & 2.5 & 3.2 \\
\hline & $\begin{array}{l}\text { Excessive amount of food close to } \\
\text { bedtime }\end{array}$ & 'Eating too much right before going to bed' & 3.3 & 3.5 & N.A. & 2.7 & 3.2 \\
\hline & $\begin{array}{l}\text { Drinking too much before } \\
\text { bedtime }\end{array}$ & $\begin{array}{l}\text { 'Drinking too much before going to sleep and therefore } \\
\text { needing to go to the toilet often' }\end{array}$ & N.A. & N.A. & N.A. & 3.2 & 3.2 \\
\hline & Did not drink enough & 'Feeling thirsty', 'Lack of water during the day' & N.A. & N.A. & N.A. & 3.0 & 3.0 \\
\hline & Inadequate amount of food & 'Feeling hungry during the night' & 2.6 & N.A. & N.A. & 3.2 & 2.9 \\
\hline
\end{tabular}


Table 3. Cont.

\begin{tabular}{|c|c|c|c|c|c|c|c|}
\hline \multirow{2}{*}{ Perceived Determinants } & \multirow{2}{*}{ Main Ideas (Merged) } & \multirow{2}{*}{ Examples of Underlying Original Ideas } & \multicolumn{4}{|c|}{ Mean Rating per Parent Group ${ }^{2}$} & \multirow[t]{2}{*}{ Mean $^{3}$} \\
\hline & & & 1 & 2 & 3 & 4 & \\
\hline \multicolumn{8}{|c|}{ Social environmental determinants } \\
\hline \multirow[t]{4}{*}{ Sleep schedule } & & & & & & & 3.5 \\
\hline & Too early bedtime & 'A bedtime that is too early for child's circadian rhythm' & N.A. & N.A. & N.A. & 3.8 & 3.8 \\
\hline & No consistent sleep schedule & $\begin{array}{l}\text { 'No consistent sleep times', 'Irregular sleep times during } \\
\text { weekends' }\end{array}$ & 3.9 & 3.5 & 3.4 & 2.8 & 3.4 \\
\hline & Daytime nap & 'Napping in the afternoon' & N.A. & 3.0 & N.A. & 3.5 & 3.3 \\
\hline \multirow[t]{5}{*}{ Family sleep habits } & & & & & & & 3.3 \\
\hline & No bedtime routine & 'Having no bedtime routine' & N.A. & 3.3 & N.A. & 3.7 & 3.5 \\
\hline & Parental absence & $\begin{array}{l}\text { 'Absence of the mother or father when the child needs } \\
\text { attention' }\end{array}$ & N.A. & 4.0 & N.A. & 2.9 & 3.5 \\
\hline & Indistinctness about bedtime & 'Not indicating clearly when the child needs to go to bed' & N.A. & 3.2 & N.A. & N.A. & 3.2 \\
\hline & Deviate from bedtime routine & $\begin{array}{l}\text { 'When the parent deviates from the usual bedtime } \\
\text { routine' }\end{array}$ & 2.6 & 2.7 & 3.4 & 3.5 & 3.1 \\
\hline \multirow[t]{3}{*}{ Social norms } & & & & & & & 2.9 \\
\hline & $\begin{array}{l}\text { Social bedtime norm among } \\
\text { siblings }\end{array}$ & $\begin{array}{l}\text { 'Older brothers or sisters that are allowed to stay up } \\
\text { longer' }\end{array}$ & N.A. & 4.2 & 2.7 & 2.8 & 3.2 \\
\hline & $\begin{array}{l}\text { Social bedtime norm among } \\
\text { classmates }\end{array}$ & $\begin{array}{l}\text { 'Other children in their class that are allowed to stay up } \\
\text { longer' }\end{array}$ & N.A. & 2.8 & 2.3 & N.A. & 2.6 \\
\hline
\end{tabular}


Table 3. Cont.

\begin{tabular}{|c|c|c|c|c|c|c|c|}
\hline \multirow{2}{*}{ Perceived Determinants } & \multirow{2}{*}{ Main Ideas (Merged) } & \multirow{2}{*}{ Examples of Underlying Original Ideas } & \multicolumn{4}{|c|}{ Mean Rating per Parent Group ${ }^{2}$} & \multirow[t]{2}{*}{ Mean $^{3}$} \\
\hline & & & 1 & 2 & 3 & 4 & \\
\hline \multicolumn{8}{|c|}{ Physical environmental determinants } \\
\hline \multirow{15}{*}{ Sleep environment } & & & & & & & 3.0 \\
\hline & Seasonal changes & 'When it is still light outside when they need to go to bed' & 2.9 & 4.0 & N.A. & 3.2 & 3.4 \\
\hline & $\begin{array}{l}\text { Absence of favourite sleep } \\
\text { accessory }\end{array}$ & $\begin{array}{l}\text { 'The absence of their favourite stuffed animal or sleeping } \\
\text { cloth' }\end{array}$ & N.A. & 2.7 & 3.1 & 4.2 & 3.3 \\
\hline & Noise outside & 'Fighting neighbours', 'Noise from the street' & N.A. & 3.6 & 2.9 & 3.5 & 3.3 \\
\hline & Not the right temperature & 'A bedroom that is too hot or too cold' & 3.1 & 3.4 & N.A. & 3.1 & 3.2 \\
\hline & Reluctant to sleep alone & $\begin{array}{l}\text { 'Wanting to stay with their parent and not wanting to } \\
\text { be alone' }\end{array}$ & 3.3 & N.A. & 3.2 & 3.0 & 3.2 \\
\hline & Uncomfortable sleeping material & $\begin{array}{l}\text { 'Uncomfortable sleeping attributes, such as pillows, } \\
\text { pyjamas, underwear' }\end{array}$ & N.A. & 3.1 & N.A. & N.A. & 3.1 \\
\hline & Too much light & 'Too much light in the bedroom' & 2.7 & 3.4 & N.A. & 3.0 & 3.1 \\
\hline & Noise inside & 'Too much noise within the home' & N.A. & N.A. & 3.0 & 3.0 & 3.0 \\
\hline & Different sleep environment & 'A different environment, not sleeping in their own bed' & N.A. & 3.0 & N.A. & 3.0 & 3.0 \\
\hline & Uncomfortable place to sleep & $\begin{array}{l}\text { 'Not having a comfortable bed and therefore not being } \\
\text { able to lay down comfortably' }\end{array}$ & N.A. & 3.0 & N.A. & 3.0 & 3.0 \\
\hline & No fresh air & 'No fresh air in the bedroom' & N.A. & 3.0 & N.A. & N.A. & 3.0 \\
\hline & Distractions in the bedroom & $\begin{array}{l}\text { 'A less tidy and messy bedroom', 'Shared bedroom with } \\
\text { brothers or sisters' }\end{array}$ & 2.8 & 3.0 & N.A. & 3.2 & 2.9 \\
\hline & Too dark & 'A bedroom that is too dark' & 2.9 & 2.9 & 2.9 & N.A. & 2.9 \\
\hline & Too quiet & 'When it is too quiet at home' & N.A. & N.A. & 2.1 & N.A. & 2.1 \\
\hline
\end{tabular}

N.A. = Not applicable, means the idea was not mentioned in this group of parents; bold values indicate that the determinant or idea was perceived as important i.e., $\geq 3.00 ;$ cursive values indicate the overall mean rating per perceived determinant; PA = Physical activity. ${ }^{1}$ The average importance ratings were based on the question: 'Think about the sleep of a child in the age of 4-12 years, how much does this affect their sleep?' answered on a 5-point Likert scale from 'does not affect at all $=1{ }^{\prime}$ to 'affects a whole lot $=5$ '. ${ }^{2}$ Groups of parents per school (i.e., schools $1-4) .{ }^{3}$ Mean importance rating of all groups of parents. 


\subsection{Perceived Determinants of Children's Inadequate Sleep}

None of the child-perceived determinants were rated as important $(\geq 3.00)$ by the children with an average score ranging from 1.9 to 2.9. However, two of the underlying main ideas were rated as important $(\geq 3.00)$ and were mentioned by all groups of children: nightmares and illness. Other underlying main ideas that were mentioned by all groups of children but had a lower overall rating for importance were: noise from inside the house, distractions in the bedroom, excitement, negative affective state, and a recent stressful event. In addition, the underlying main ideas that did have a high importance score but were only mentioned in some groups of children were: a recent scary event, scary thoughts, not the right temperature, not being able to lie down comfortably, having too many thoughts, an upcoming stressful event, not being tired and going to bed too early.

Almost all parent-perceived determinants and their underlying main ideas were rated as important ( $\geq 3.00$ ) ranging from 2.9 to 3.9 , and 2.1 to 4.4 , respectively. The underlying main ideas that were mentioned by all groups of parents were: illness, parental relationship problems, being bullied, an upcoming stressful event, a recent stressful event, no consistent sleep schedule, watching something scary, screen use before bedtime, deviating from bedtime routine. The underlying main idea with the highest importance rating was feeling unsafe (mean rating of 4.4).

Most of the determinants mentioned by parents were also mentioned by children. However, the same ideas were often clustered differently by parents and children: 1) 'physical well-being' (parents) versus 'discomfort' and 'diet' (children); 2) 'affective state' and 'stressful situation' (parents) versus 'affective state' (children); 3) 'energy' and 'physical activity' (parents) versus energy (children); 4) 'sleep schedule'; 5) 'sleep environment'; and 6) 'activating activities' (parents) versus 'screen behaviour' (children). Potential determinants that were mentioned by parents but not by children were 'family sleep habits' and 'social environment'.

\section{Discussion}

The aim of this study was to explore potential determinants of children's inadequate sleep health, from the perspective of school-aged children and parents living in low-SEP neighbourhoods. These perspectives brought about important insights, which can inform future intervention development to promote healthy sleep. Both children and parents identified various potential determinants of children's inadequate sleep health which were categorized into psychological (i.e., fear, affective state), social environmental (e.g., sleep schedule, stressful situation), behavioural (e.g., screen behaviour, physical activity, diet), physical environmental (i.e., sleep environment), and physiological (i.e., discomfort, physical well-being) determinants.

Fear was rated by children as most important. They described fear due to a recent scary event, reading or watching something scary, hearing scary sounds, or having a nightmare. Parents also rated affective state, including being afraid, as important. A recent review (2019) [16] found inconclusive evidence for a relationship between anxiety symptoms and sleep duration, and no evidence for a relationship with sleep quality. However, the results in this review are based on only two longitudinal studies. Additionally, Bagley et al. (2015) found that pre-sleep worries mediated the relationship between family income and children's sleep health based on cross-sectional data [24]. Potentially, those who experienced anxiety engaged in unhelpful pre-bedtime behaviours [25]. Both children and parents in the current study rated the perceived psychological determinants, fear and affective state, as important, and these determinants included many underlying ideas. Consequently, dealing with fear or other negative affective feelings before falling asleep, concurrent with good sleep hygiene practices, may be a promising focus when promoting healthy sleep. This may be included in healthy sleep interventions by teaching children relaxation techniques, such as meditation, breathing exercises, imagination journeys [26] in both school, after-school and community settings. Additionally, teaching parents (i.e., online or through community programmes) how to implement such techniques in their child's bedtime routine could be an important avenue for promoting healthy sleep. 
Both children and parents identified a stressful situation (e.g., being bullied, parental stress, and parental relationship problems) as a potential determinant of inadequate sleep. This aligns with the results of a review that concluded that children who live in a supportive family environment and have a healthy relationship with their parents generally sleep longer and more efficiently [27]. A supportive and healthy family environment is characterized by parents' involvement in their child's life, and a good relationship between the child and its caregivers [27]. This also means parents should be aware of whether their child is going through a difficult time and support their child when needed (e.g., when the child has had a negative experience such as being bullied). Furthermore, one longitudinal study found that parent-child physical conflict (i.e., verbal aggression such as screaming, and physical aggression such as beating) was a determinant of children's insufficient sleep duration [28]. Our findings support existing evidence that creating a positive and supportive family environment is important for healthy sleep. It may therefore be valuable to encourage parents to monitor their child's needs, desires and stressors. Such interventions may include letting parents re-evaluate their behaviour, giving scenario-based risk information, or raising consciousness to increase parents' awareness [15]. Increasing awareness must be quickly followed by increasing parent's problem-solving ability and self-efficacy (i.e., confidence in their ability) by using methods such as goal setting, self-monitoring of behaviour, setting graded tasks, and planning coping responses [15]. This may reach parents via face-to-face or web-based sessions.

An inadequate sleep schedule, including an inappropriate bedtime (i.e., too early or late), an inconsistent sleep schedule (i.e., varying bedtimes throughout the week and weekend) and daytime napping, was identified by both children and parents as determinant of inadequate sleep. Additionally, parents identified the determinant 'family sleep habits', including not having or deviating from a bedtime routine, indistinctness about the child's bedtime, and parental absence when the child needs attention. This finding aligns with the conclusions of previous reviews, and confirms parents' critical role in children's sleep hygiene $[16,17,29]$. Consequently, future sleep interventions may include enhancing parent's self-efficacy and sleep-related parenting skills, e.g., to create and adhere to a consistent sleep schedule and a relaxing bedtime routine. Parents' self-efficacy may be increased by using a method such as self-monitoring of behaviour, for which parents log the sleep schedule and bedtime routine activities of their child and subsequently receive feedback on these logs from a health professional [15].

Four perceived behavioural determinants were identified; energy, physical activity, activating activities, and dietary behaviour. It is generally accepted that adequate physical activity during the day promotes sleep at night $[30,31]$. This presumable relationship seems to be bidirectional, as the quantity and quality of sleep also seems related to physical activity the following day [32,33], creating a vicious circle [31]. Sleep is also related to diet [32,34]. Although most studies investigate inadequate sleep as a determinant of unhealthy dietary behaviours, the evidence for the bi-directionality of this relationship is growing [35]. In addition, a recent review among healthy adults [36] found that sleep was only impaired after vigorous intensity exercise, ending $\leq 1 \mathrm{~h}$ before bedtime. Furthermore, stimulating activities, including screen behaviours, are also generally acknowledged as important determinants of children's inadequate sleep [37]. Such activities increase alertness, through several mechanisms: sleep time displacement, psychological stimulation and light exposure [38]. Encouraging sensible screen behaviours before bedtime (e.g., no agitating screen-based activities, avoiding screens in the bedroom) seems a promising element of future sleep interventions, but must be combined with other sleep hygiene strategies, e.g., regular bedtimes and a bedtime routine [38]. To conclude, these interactions and bidirectional relationships show that healthy sleep and its determinants should be included in healthy lifestyle interventions for children. To date, these interventions mainly focused on promoting a healthy diet and adequate amounts of physical activity [39].

Shortcomings in children's sleep environment, including too much light, not the right temperature, noise, uncomfortable sleeping place, uncomfortable sleep materials, and distractions in the bedroom, were identified as potential determinants. This finding is partly in line with Bagley et al. who found 
that temperature and noise were associated with more sleep-wake problems in 10-13 year olds, while the amount of light was not related to any of their sleep outcomes [24]. The review by Allen et al. also showed limited support for adjusting the bedroom light to as dark (i.e., only two studies) and as quiet (i.e., only two studies) as possible for better sleep [17]. In contrast, a recent review of the WHO found evidence for a relationship between ambient noise and inadequate sleep [40]. Furthermore, a previous study (2017) where 11-12 year old multi-ethnic adolescents identified sleep-disturbing household activities, found that disorganization in the home environment such as TV or noise disturbance, family members phone calling, or night-time home visitors, were related to disturbed sleep [41]. In conclusion, environmental factors can be sleep-disrupting for some children, depending on children's individual preferences for the amount of light, room temperature, noise level, and other distractions.

\subsection{Strengths and Limitations}

A strength of this study is that it provides valuable and new information about potential determinants of children's inadequate sleep as seen from the perspective of children and their parents. These perspectives are relevant for future healthy sleep interventions. Moreover, this is one of the first studies that specifically focuses on families living in low SEP neighbourhoods. The potential determinants identified in this study may also be relevant for children living in middle and high SEP areas, however, future research is needed to confirm this. The broad focus on all aspects of inadequate sleep (duration, quality) further strengthens this study. However, there were also some limitations. Firstly, the concept mapping method makes use of a focus statement, which forces the researcher to choose one side of the health behaviour (i.e., positive or negative). This study focused on inadequate sleep, which inevitably neglects specific facilitators of healthy sleep. Secondly, potential personal determinants of which participants are unaware, e.g., unhelpful beliefs, may be overlooked. This may be included in future studies by incorporating follow-up questions focused on beliefs in the brainstorm session. Thirdly, it was not always clear why the children grouped certain ideas together. To give an example: a child (group 4A) clustered 'In bed, thinking about something scary that I experience' together with 'A brother or sister that keeps me awake'. We therefore recommend that future concept mapping studies incorporate time to ask children to explain their clusters. Lastly, we did not screen the participating children and parents on potential sleep problems or other medical conditions. There is a possibility that poor sleepers and parents whose children have trouble sleeping were more interested in participating in this study despite the emphasis on recruiting children and parents with both adequate and inadequate sleep health.

Overall, all determinants were rated lower on importance by children than parents. A possible explanation may be found in the use of a smiley face Likert scale, as children tend to choose happy smiley faces rather than unhappy and very unhappy faces [42]. For future studies, we therefore recommend using smiley scales with only positive responses, varying in degree of happiness [42]. Although children's importance ratings were lower in general, they still provided insight into the relative importance of determinants according to children.

\subsection{Implications for Research and Practice}

Our study identified potential determinants of children's inadequate sleep health, of which the majority have not been studied thoroughly. Future research is therefore needed to confirm whether these are actual determinants of children's inadequate sleep. In studying determinants of sleep, conducting a longitudinal study is not always required, as many psychological and social environmental determinants have acute effects. A suitable method would be ecological momentary assessment, for which potential determinants (e.g., affective state) are measured before bedtime and linked to subsequent sleep [43].

This study provides a broad overview of the perspectives of children and parents on potential determinants of children's inadequate sleep. Our findings suggest that children's sleep is affected by multiple interrelated and interacting determinants within the personal (i.e., physical, psychological and 
behavioural), social- and physical environment, which is in line with the social ecological model [15] and the 'determinants of health' model of Dahlgren and Whitehead [44]. This implies that a multilevel and multifactorial intervention is recommended to promote healthy sleep [45].

The results of our concept mapping study show that children's inadequate sleep is a complex problem, with many different and interacting determinants on several levels of the social ecological model [15]. Such complex problems demand a systems approach [46,47], where relevant determinants of children's sleep health are targeted at multiple levels of the system. Furthermore, children and parents identified many potential determinants in the current study. However, the relevance of these determinants might differ per child. For the development of a relevant healthy sleep intervention, we therefore recommend working closely with children and parents.

\section{Conclusions}

Both children and parents identified various potential psychological (i.e., fear, affective state, stressful situation), social environmental (i.e., sleep schedule, family sleep habits), behavioural (i.e., screen behaviour, physical activity, diet), physical environmental (i.e., sleep environment), and physiological (i.e., physical well-being) determinants of children's inadequate sleep health. These findings indicate that children and parents perceive children's sleep health to be influenced by multiple determinants at different levels, and that children's sleep health requires promotion through systemic, multilevel and multifactorial action.

Author Contributions: L.S.B., V.B., L.M.H., M.M.v.S., I.A.H., and M.J.M.C. conceptualized and designed the research project; L.S.B., V.B., M.M.v.S. and I.A.H. collected the data; L.S.B., V.B., D.P.M.S., M.M.v.S., and M.J.M.C. analysed and interpreted the data; L.S.B. wrote the initial manuscript and all other authors contributed to writing and editing the manuscript. All authors have read and agreed to the published version of the manuscript.

Funding: This research was funded by the Amsterdam Healthy Weight Approach, Public Health Service (GGD), City of Amsterdam, Amsterdam, the Netherlands and scientific research institute Sarphati Amsterdam, Public Health Service (GGD), City of Amsterdam, Amsterdam, the Netherlands.

Acknowledgments: The authors thank Liesbet Boterdaele (Ghent University) and Rian Pepping (Public Health Service Amsterdam) for their help with the data collection and data entry; Eline Roordink (Vrije Universiteit Amsterdam), Eline Vos (Amsterdam University Medical Center) and Anouk Wisse (Public Health Service Amsterdam) for their help with the data collection; Froukje Takens (Amsterdam University Medical Center) for her help with the recruitment of schools and in carrying out the pilot study; and Sanne Veldman (Amsterdam University Medical Center) for improving the quality of our manuscript text. The authors also thank Sarphati Amsterdam and the Amsterdam Healthy Weight Approach for funding this research.

Conflicts of Interest: The authors declare no conflict of interest.

\section{Abbreviations}

A.W.: Anouk Wisse; D.P.M.S.: Dominique Patricia Maria Stijnman; E.M.R.: Eline Maria Roordink; E.E.V.: Eline Eva Vos; I.A.H.: Irene Anhai Harmsen; L.S.B.: Laura Shanna Belmon, L.B.: Liesbet Boterdaele; L.M.H.: Lisan Mariët Hidding; M.M.v.S.: Maartje Marieke van Stralen; M.J.M.C.: Mai Jeanette Maidy Chinapaw; R.P.: Rian Pepping; V.B.: Vincent Busch. 


\section{Appendix A}

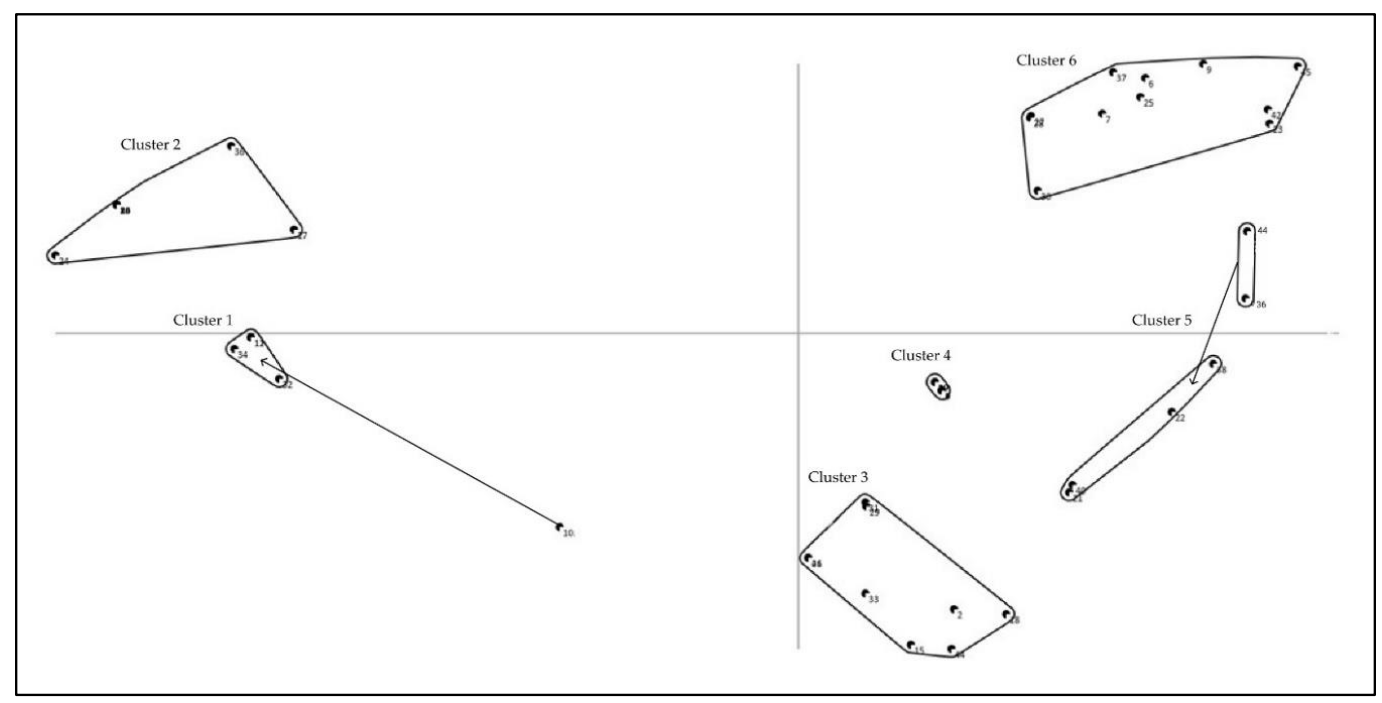

Figure A1. Concept map children, group 1. In this map, each point reflects one idea. Ideas that were grouped together more often appear closer to each other on the map. Ideas never/rarely grouped together appear widely separated on the map. Clusters are groups of ideas that were grouped together most often and reflect ideas that are conceptually related according to the participants in this group. The defined cluster names in this concept map were: Cluster 1: Screen behaviour; Cluster 2: Noise, distractions and light; Cluster 3: Being unable or reluctant to sleep; Cluster 4: Illness or restless; Cluster 5: Stressful and exciting thoughts and feelings; Cluster 6: Being afraid or uncomfortable in bed. Arrows indicate an idea is reallocated by researchers; idea 10 'Watching series in bed and wanting to keep watching' was reallocated to Cluster 1, and idea 36 'Being bullied at school and thinking about the next day when I am in bed' and 44 'Feeling sad' were reallocated to Cluster 5.

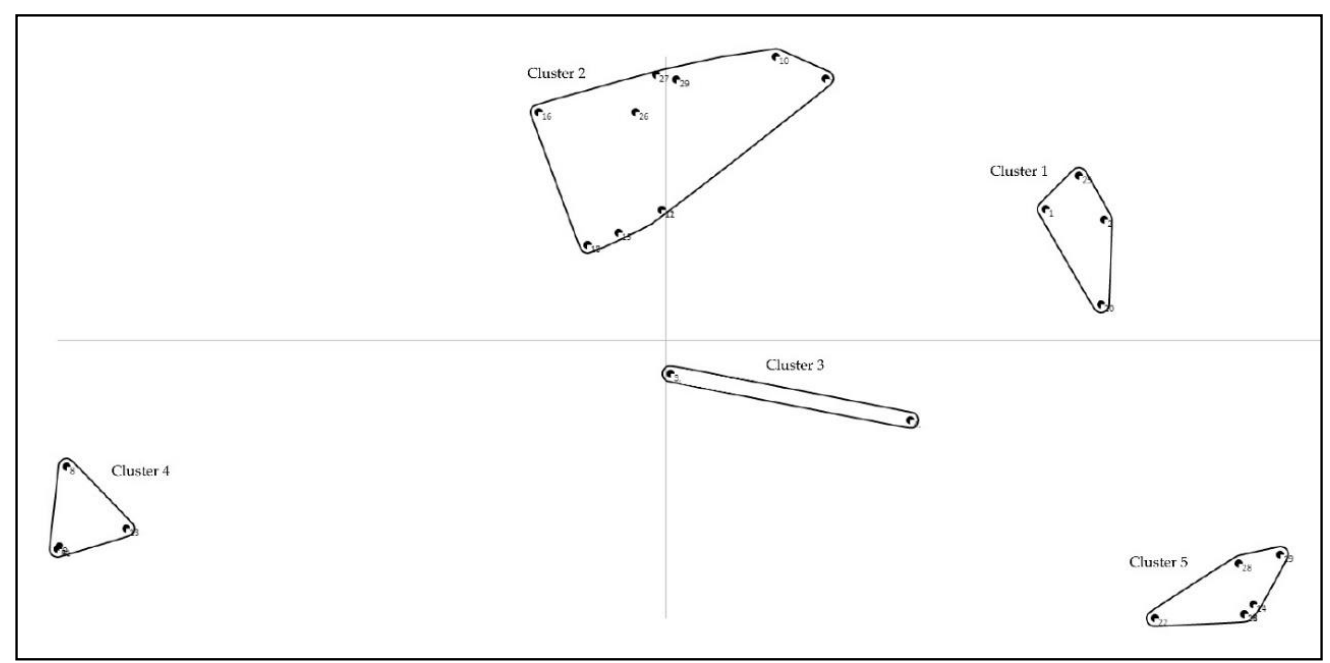

Figure A2. Concept map children, group 2. In this map, each point reflects one idea. Ideas grouped together more often appear closer to each other on the map. Ideas never/rarely grouped together appear widely separated on the map. Clusters are groups of ideas that were grouped together most often and reflect ideas that are conceptually related according to the participants in this group. The defined cluster names in this concept map were: Cluster 1: Being scared; Cluster 2: Stressful and exciting thoughts and feelings, and illness; Cluster 3: Light in the bedroom; Cluster 4: Noise and distractions in the bedroom; Cluster 5: Fear. 


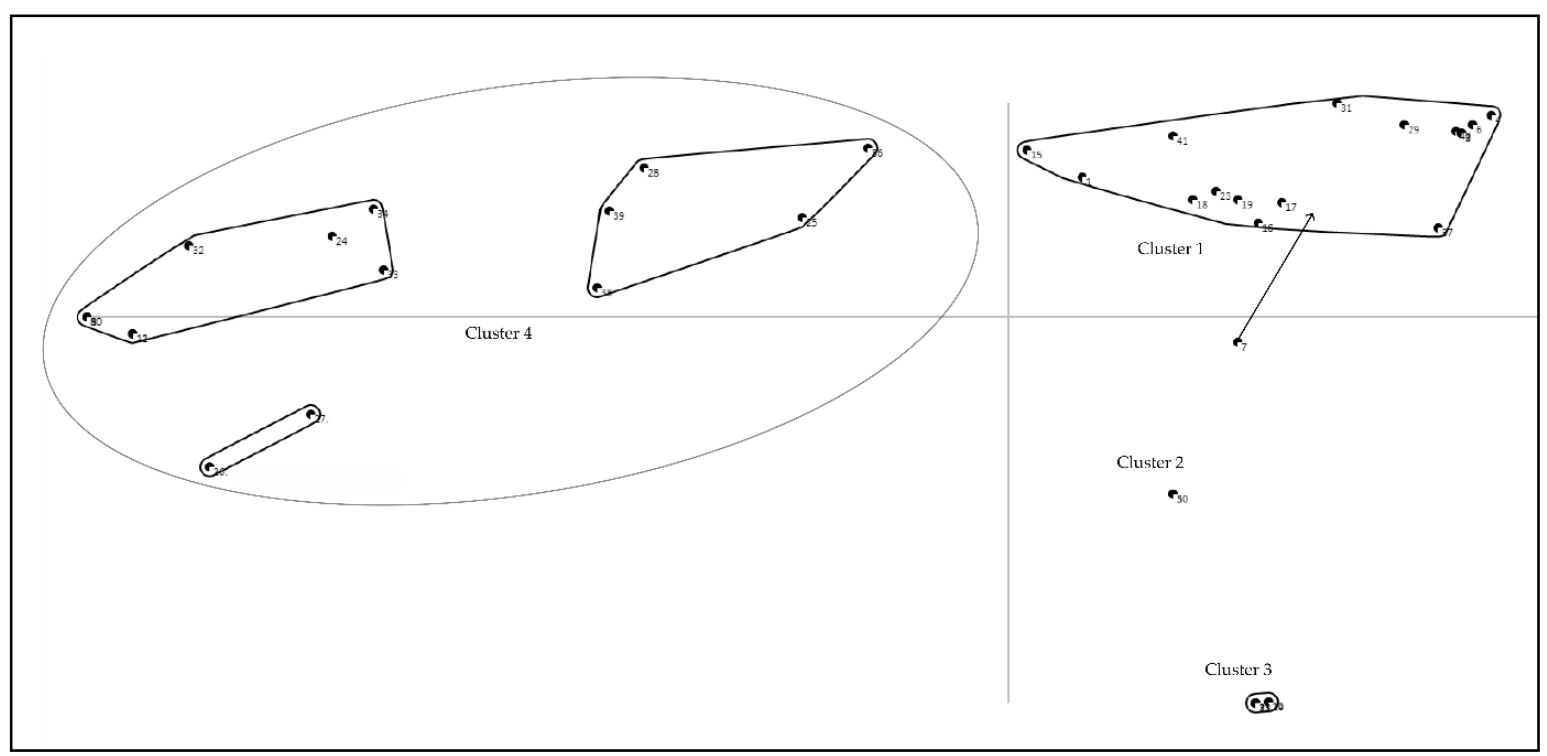

Figure A3. Concept map children, group 3A. In this map, each point reflects one idea. Ideas grouped together more often appear closer to each other on the map. Ideas never/rarely grouped together appear widely separated on the map. A circle means that a new cluster is created by the researchers, by combining original clusters. Clusters are groups of ideas that were grouped together most often and reflect ideas that were related conceptually according to the participants in this group. The defined cluster names in this concept map were: Cluster 1: Unable or reluctant to sleep; Cluster 2: Uncomfortable in bed; Cluster 3: Illness and discomfort; Cluster 4: Stressful and exciting thoughts and feelings. Arrows indicate an idea is reallocated by researchers; idea 7 'My parents who make noise in our home' was moved to Cluster 1.

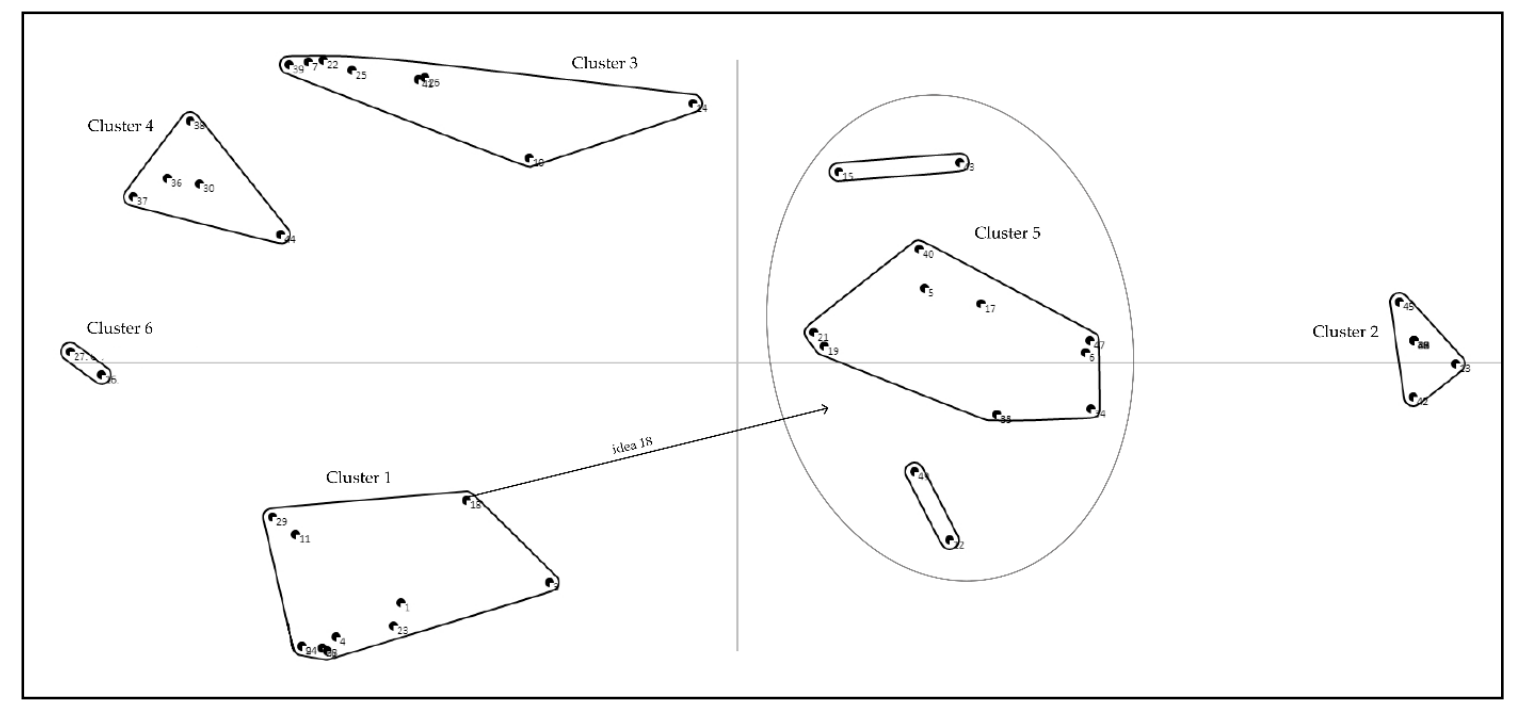

Figure A4. Concept map children, group 3B. In this map, each point reflects one idea. Ideas grouped together more often appear closer to each other on the map. Ideas never/rarely grouped together appear widely separated on the map. A circle means that a new cluster is created by the researchers, by combining original clusters. Clusters are groups of ideas that were grouped together most often and reflect ideas that were related conceptually according to the participants in this group. The defined cluster names in this concept map were: Cluster 1: Stressful and exciting thoughts and feelings; Cluster 2: Noise and distractions in the bedroom; Cluster 3: Illness and discomfort; Cluster 4: Emotions; Cluster 5: Unable or reluctant to sleep; Cluster 6: General negative state of mind. Arrows indicate an idea is reallocated by researchers; idea 18 'Not feeling like going to sleep' was moved to Cluster 5. 


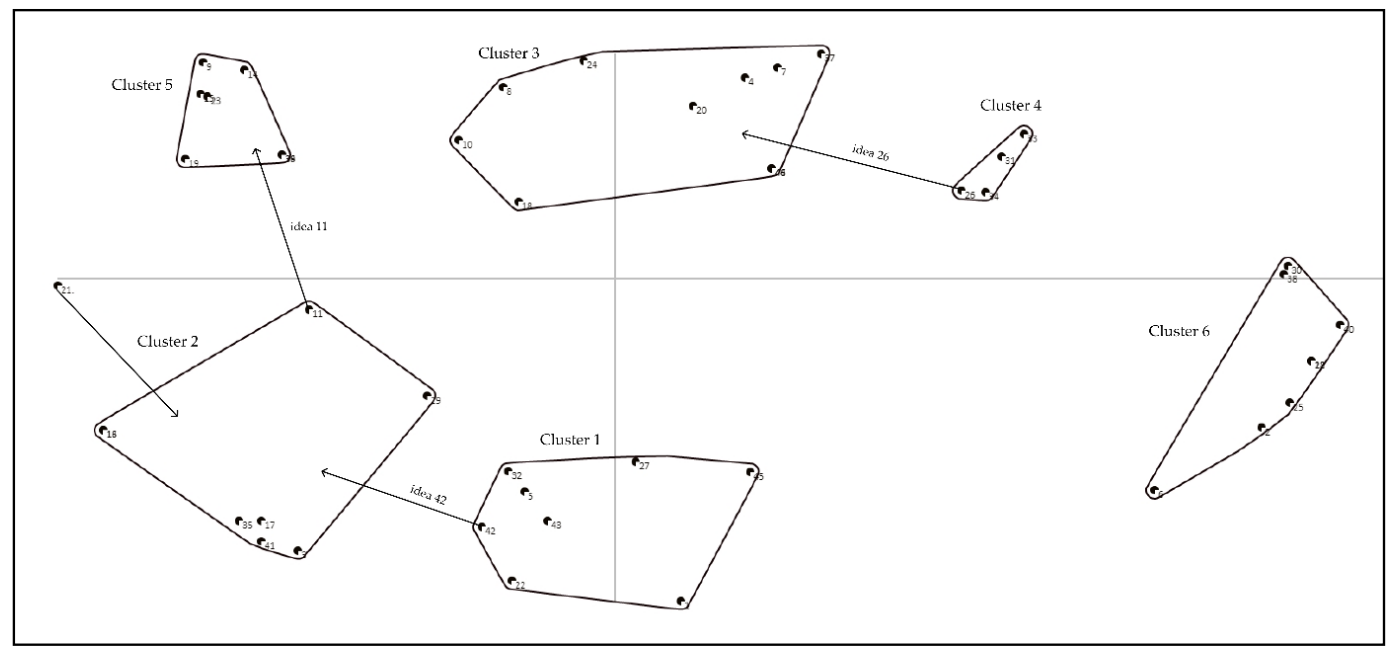

Figure A5. Concept map children, group 4A. In this map, each point reflects one idea. Ideas grouped together more often appear closer to each other on the map. Ideas never/rarely grouped together appear widely separated on the map. Clusters are groups of ideas that were grouped together most often and reflect ideas that were related conceptually according to the participants in this group. The defined cluster names in this concept map were: Cluster 1: Stressful thoughts and feelings; Cluster 2: Noise, distractions, and stressful family situation; Cluster 3: Unable or reluctant to sleep; Cluster 4: Stressed for the upcoming day; Cluster 5: Discomfort; Cluster 6: Being afraid. Arrows indicate an idea is reallocated by researchers; idea 11 'Needing to pee when I am already in bed' was moved from Cluster 2 to Cluster 5; idea 21 'The sound of whizzing in my ears when it is very quiet' was moved to Cluster 2; idea 26 'Still feel like playing' was moved from Cluster 4 to Cluster 3; idea 42 'The sound of the TV is too loud when I am in bed' was moved from Cluster 1 to Cluster 2.

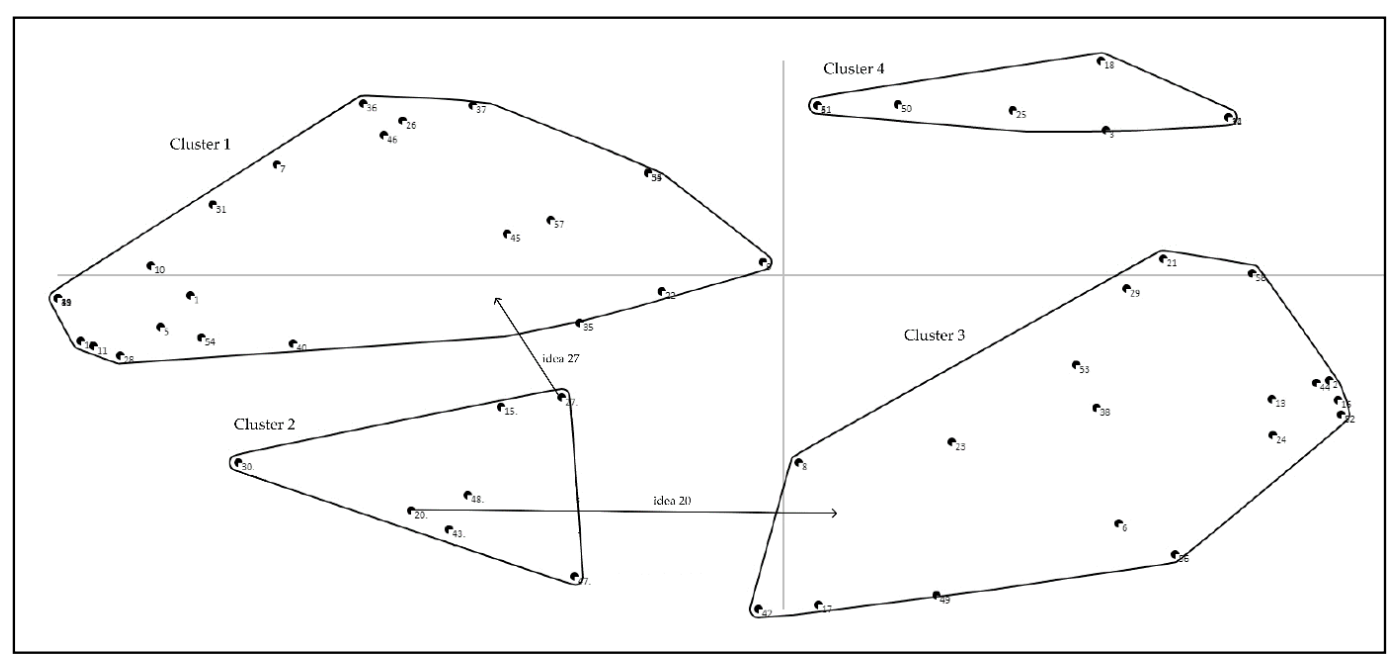

Figure A6. Concept map children, group 4B. In this map, each point reflects one idea. Ideas grouped together more often appear closer to each other on the map. Ideas never/rarely grouped together appear widely separated on the map. Clusters are groups of ideas that were grouped together most often and reflect ideas that were conceptually related according to the participants in this group. The defined cluster names in this concept map were: Cluster 1: Unable or reluctant to sleep; Cluster 2: Noise and distractions in the bedroom; Cluster 3: Stressful and exciting thoughts and feelings and stressful family situation; Cluster 4: Agitating activities before bedtime and being afraid. Arrows indicate an idea is reallocated by researchers; idea 20 'Sleeping at daytime' was moved from Cluster 2 to Cluster 3; idea 27 'Thinking about someone I love and is not amongst us anymore' was moved from Cluster 2 to Cluster 1. 

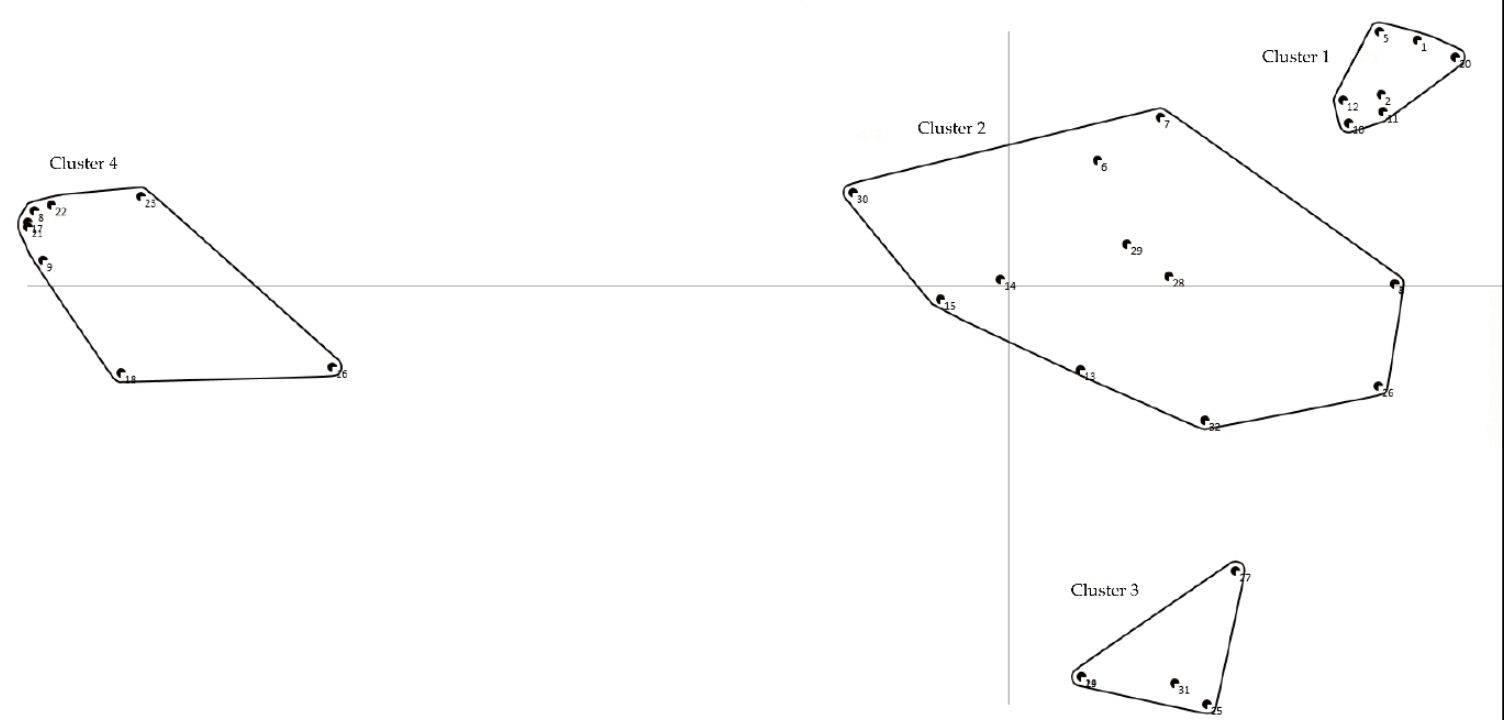

Figure A7. Concept map parents, group 1. In this map, each point reflects one idea. Ideas grouped together more often appear closer to each other on the map. Ideas never/rarely grouped together appear widely separated on the map. Clusters are groups of ideas that were grouped together most often and reflect ideas that were related conceptually according to the participants in this group. The defined cluster names in this concept map were: Cluster 1: Energy, diet, and physical activity; Cluster 2: Stressful and exciting thoughts and feelings, physical well-being, routines and screen behaviour; Cluster 3: Stressful family or school situation; Cluster 4: Sleep environment.

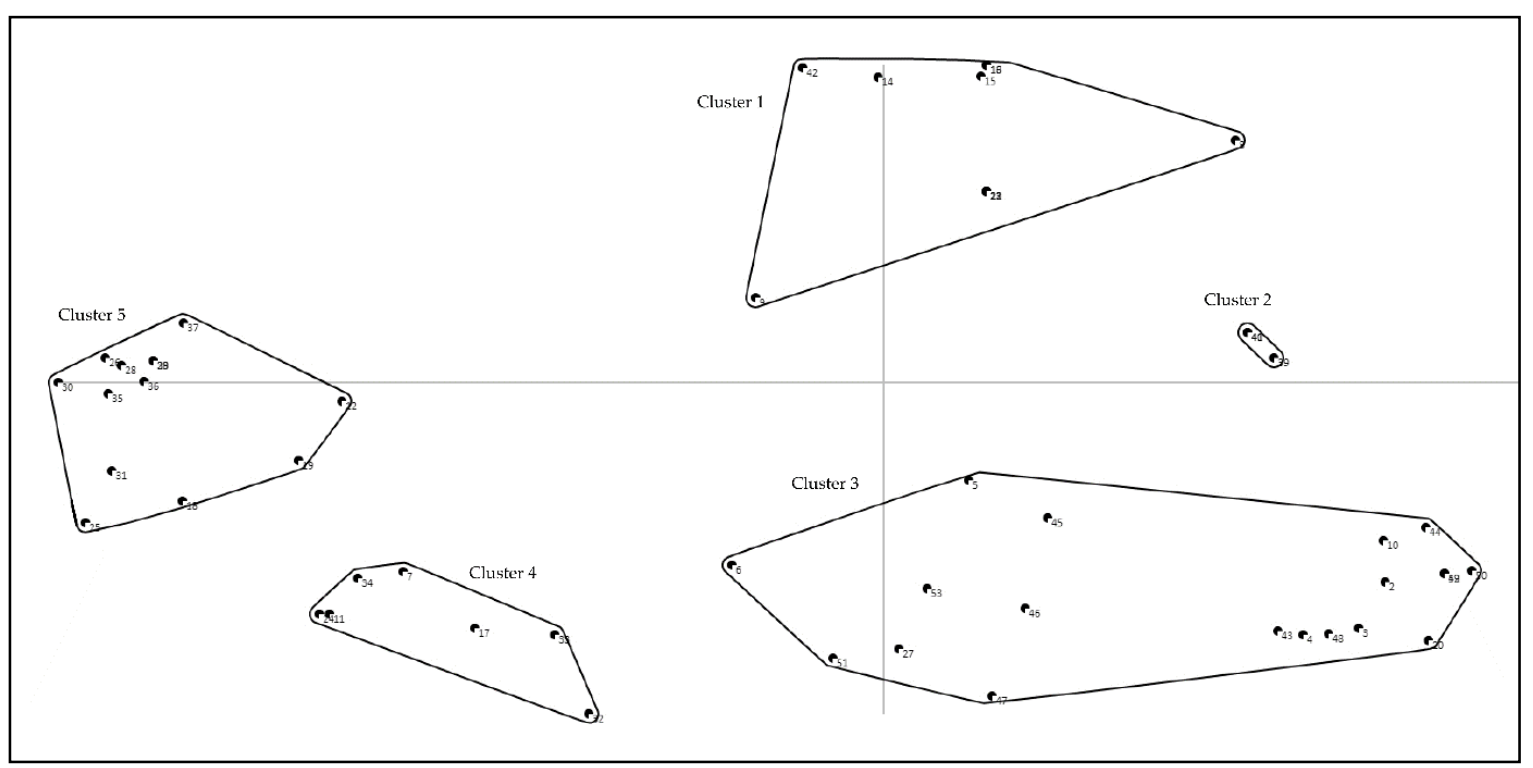

Figure A8. Concept map parents, group 2. In this map, each point reflects one idea. Ideas grouped together more often appear closer to each other on the map. Ideas never/rarely grouped together appear widely separated on the map. Clusters are groups of ideas that were grouped together most often and reflect ideas that were related conceptually according to the participants in this group. The defined cluster names in this concept map were: Cluster 1: Diet, physical activity, and screen behaviour; Cluster 2: Noise from the neighbours; Cluster 3: Mental distress, physical well-being, and stressful family situation; Cluster 4: Routines and social environment; Cluster 5: Sleep environment and bedtime routine. 


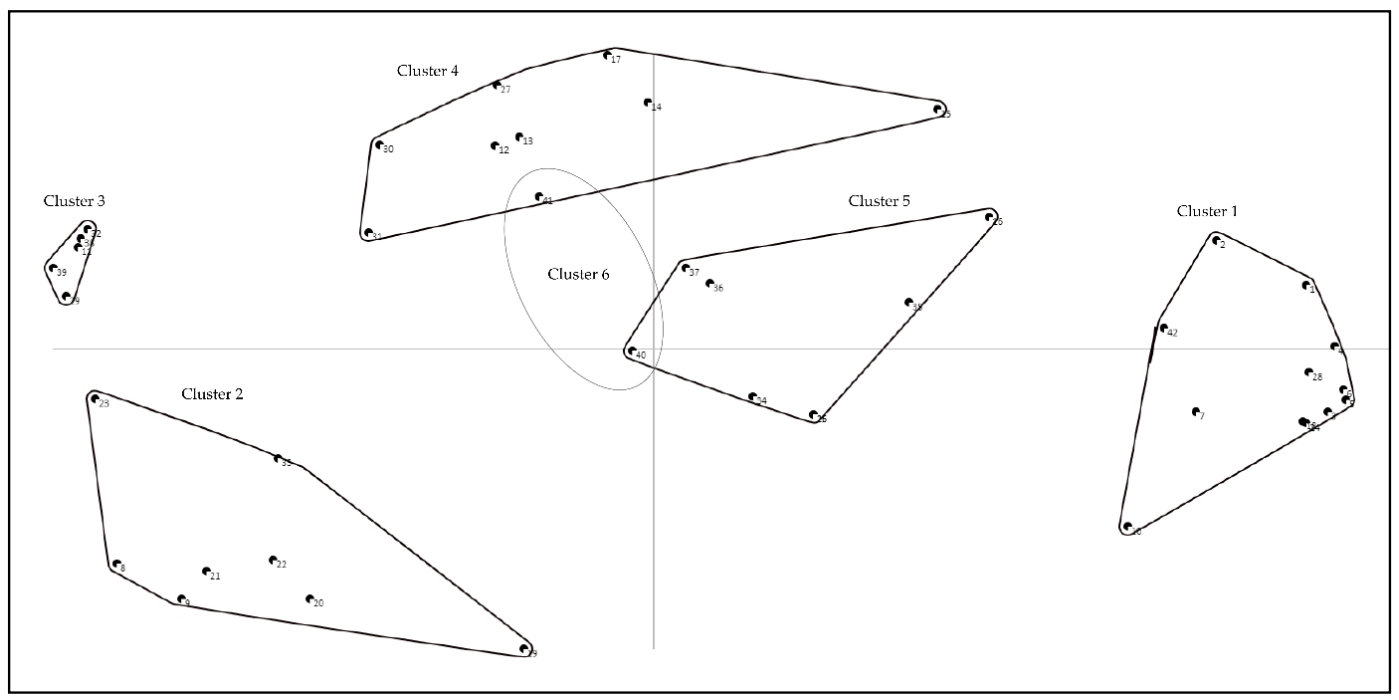

Figure A9. Concept map parents, group 3. In this map, each point reflects one idea. Ideas grouped together more often appear closer to each other on the map. Ideas never/rarely grouped together appear widely separated on the map. A circle means that a new cluster is created by the researchers, taking two ideas from two different clusters (cluster 4 and 5). Clusters are groups of ideas that were grouped together most often and reflect ideas that were related conceptually according to the participants in this group. The defined cluster names in this concept map were: Cluster 1: Concept map parents, group 3. Mental distress and active brain; Cluster 2: Family- and social environment; Cluster 3: Sleep environment; Cluster 4: Stressful family situation, worries and fear; Cluster 5: physical- and mental well-being; Cluster 6: Screen behaviour before bedtime.

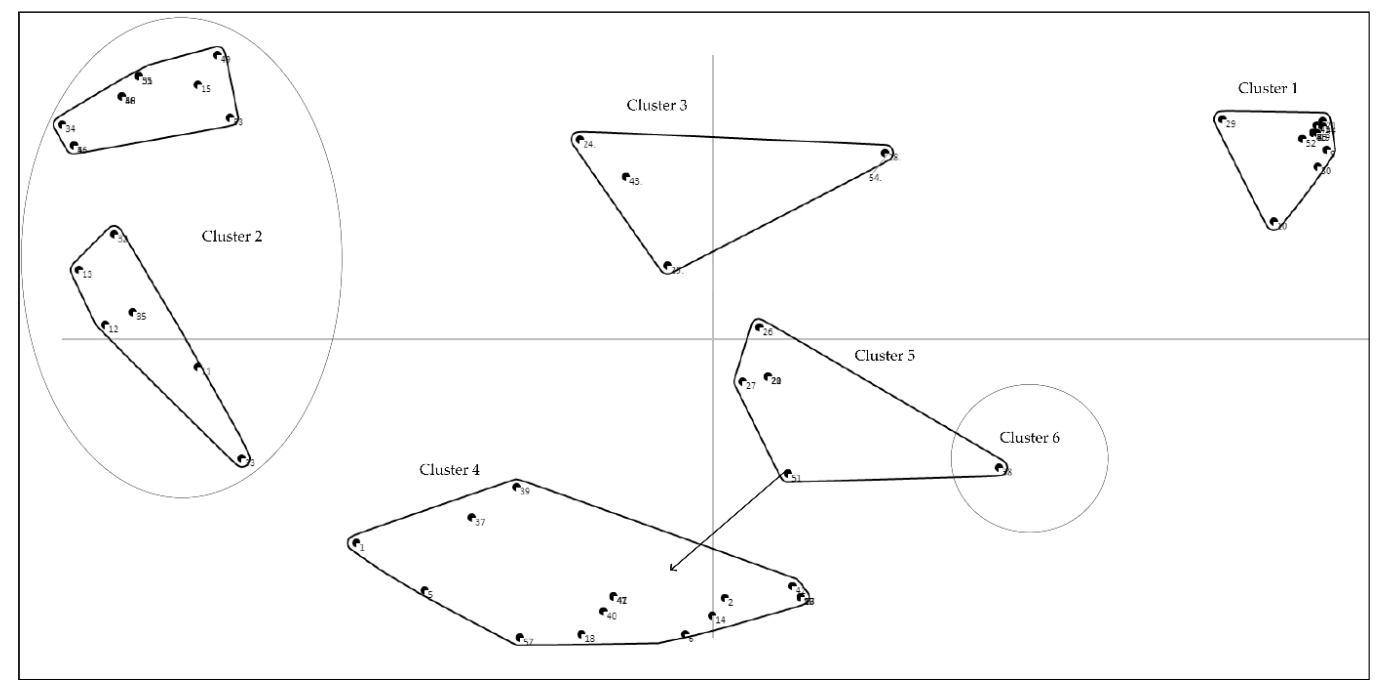

Figure A10. Concept map parents, group 4. In this map, each point reflects one idea. Ideas grouped together more often appear closer to each other on the map. Ideas never/rarely grouped together appear widely separated on the map. A circle means that a new cluster is created by the researchers; Cluster 2 is a combination of two identified clusters. Clusters are groups of ideas that were grouped together most often and reflect ideas that were related conceptually according to the participants in this group. The defined cluster names in this concept map were: Cluster 1: Sleep environment; Cluster 2: Mental distress, stressful family situation, worries, and fear; Cluster 3: Family environment and sleep habits; Cluster 4: Energy, diet, physical activity, and routines; Cluster 5: Screen behaviour and bedtime routine; Cluster 6: Physical well-being. Arrows indicate an idea is reallocated by researchers; idea 51 'Having a jetlag' was moved from Cluster 5 to Cluster 4. 


\section{Appendix B}

Table A1. Cluster compositions of original ideas and mean importance ratings of children in group 1 $(N=8)$, including the assignment of original ideas to main ideas $(N=6)$.

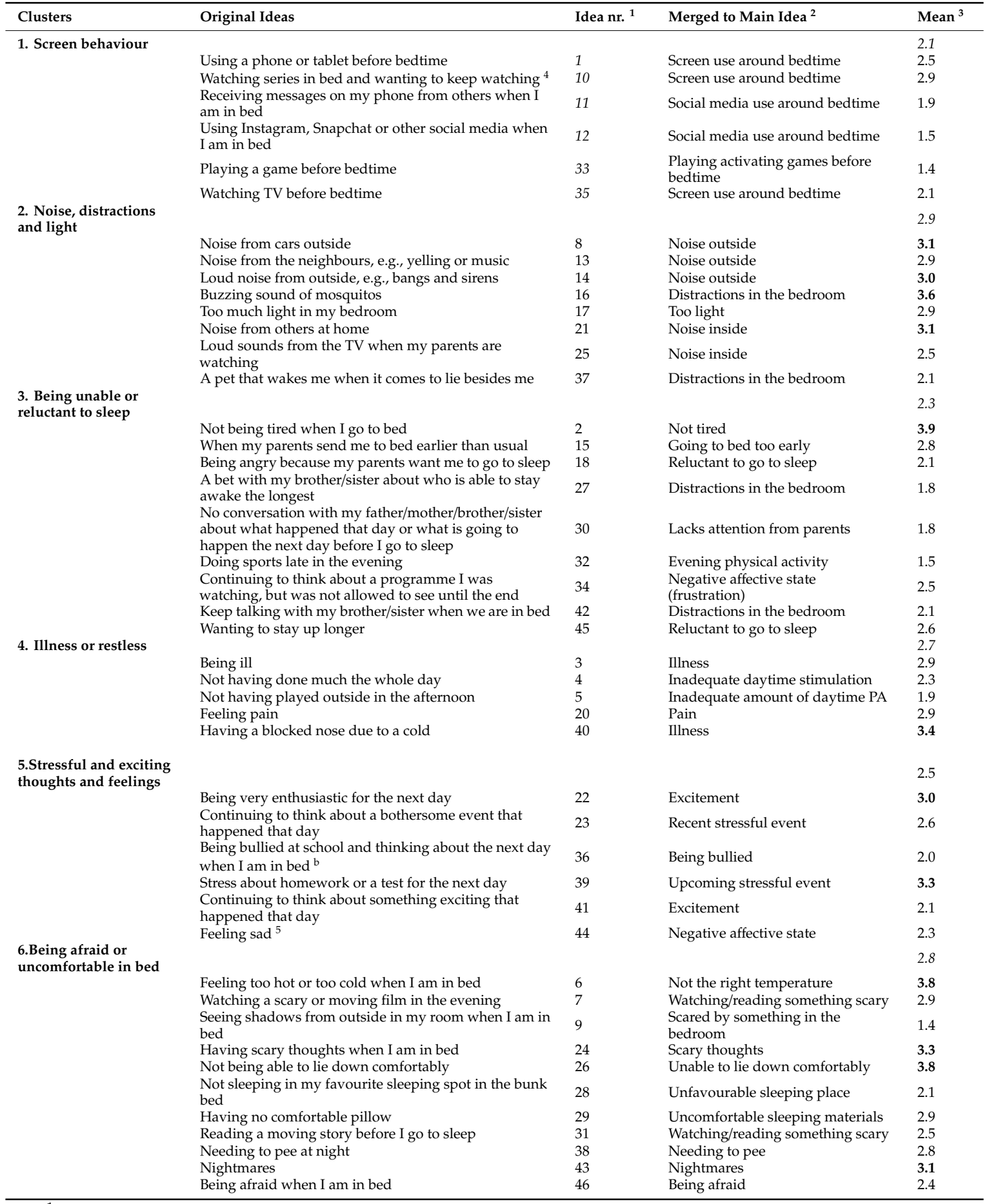

${ }^{1}$ Idea nr. $=$ The number of the generated idea in this group. This corresponds with the numbers on the concept maps in Appendix A. ${ }^{2}$ Merged into main idea $=$ The overall main idea to which the original idea of this group is assigned. ${ }^{3}$ Mean $=$ mean importance rating on a 5 -point Likert scale based on the question: "Think about your sleep, how much does this affect your sleep?' answered on a 5-point Likert scale from 'does not affect at all $=1$ ' to 'affects a whole lot' $=5^{\prime} ;{ }^{4}$ idea was moved to cluster $1 ; 5$ idea was moved to cluster 5 . Bold values indicate ideas rated as important (with a rating $\geq 3.00$ ); Cursive values indicate the overall mean rating per cluster. 
Table A2. Cluster compositions of original ideas and mean importance ratings of children in group 2 $(N=5)$, including the assignment of original ideas to main ideas.

\begin{tabular}{|c|c|c|c|c|}
\hline Clusters & Original Ideas & Idea nr. ${ }^{1}$ & Merged to Main Idea ${ }^{2}$ & Mean $^{3}$ \\
\hline \multirow[t]{5}{*}{ 1. Being afraid } & & & & 3.0 \\
\hline & Watching a scary movie before bedtime & 1 & Watching/reading something scary & 3.0 \\
\hline & Nightmares & 2 & Nightmares & 3.2 \\
\hline & Stuff in my room that looks scary when I am in bed & 21 & $\begin{array}{l}\text { Scared by something in the } \\
\text { bedroom }\end{array}$ & 2.2 \\
\hline & Doing something I find scary at daytime & 26 & Recent scary event & 3.6 \\
\hline \multirow{12}{*}{$\begin{array}{l}\text { 2. Stressful and exciting } \\
\text { thoughts and feelings, and } \\
\text { illness }\end{array}$} & & & & 2.9 \\
\hline & Thinking about something scary when I am in bed & 7 & Scary thoughts & 3.2 \\
\hline & $\begin{array}{l}\text { In my bed, thinking about bad events that I } \\
\text { experienced in the past }\end{array}$ & 11 & Recent stressful event & 2.6 \\
\hline & Going to do something stressful the next day & 12 & Upcoming stressful event & 3.0 \\
\hline & Going to do something exciting the next day & 13 & Excitement & 3.0 \\
\hline & Feeling sad when I am in bed & 16 & Negative affective state & 2.8 \\
\hline & Thinking about something sad when I am in bed & 17 & Negative affective state & 2.8 \\
\hline & Being ill & 18 & Illness & 3.4 \\
\hline & Feeling pain & 19 & Pain & 3.0 \\
\hline & Feeling guilty about something I did that day & 27 & Negative affective state & 3.0 \\
\hline & $\begin{array}{l}\text { In my bed, thinking about something I experienced } \\
\text { that day during sports }\end{array}$ & 28 & Recent stressful event & 2.4 \\
\hline & Being angry about something that I find unfair & 30 & Negative affective state & 3.0 \\
\hline \multirow[t]{3}{*}{ 3. Light in the bedroom } & & & & 2.4 \\
\hline & A bedroom that is too light & 3 & Too much light & 3.0 \\
\hline & A bedroom that is too dark & 4 & Too dark & 1.8 \\
\hline \multirow{7}{*}{$\begin{array}{l}\text { 4. Noise and distractions in } \\
\text { the bedroom }\end{array}$} & & & & 2.8 \\
\hline & Loud noise from the neighbours when I am in bed & 5 & Noise outside & 3.0 \\
\hline & Loud noise from outside when I am in bed & 6 & Noise outside & 4.2 \\
\hline & Scary sounds when I am in bed & 8 & Noise outside & 2.8 \\
\hline & $\begin{array}{l}\text { Sleeping together in a bedroom with my } \\
\text { brother/sister who makes sounds }\end{array}$ & 9 & Distraction in the bedroom & 1.8 \\
\hline & A brother or sister that keeps me awake & 14 & Distraction in the bedroom & 3.0 \\
\hline & $\begin{array}{l}\text { Hearing the sound from the TV when my parents } \\
\text { are watching TV and I am in bed }\end{array}$ & 22 & Noise inside & 2.2 \\
\hline \multirow[t]{6}{*}{ 5. Fear } & $\begin{array}{l}\text { Being home alone and afraid that my } \\
\text { parents/brother/sister do not come home }\end{array}$ & 15 & Scary thoughts & 4.0 \\
\hline & Being afraid that someone breaks into my home & 20 & Scary thoughts & 4.0 \\
\hline & $\begin{array}{l}\text { Suddenly not hearing any sounds from my parents } \\
\text { in our home when I am in bed }\end{array}$ & 23 & Scary thoughts & 3.6 \\
\hline & Being afraid that my parents are not at home & 24 & Scary thoughts & 4.0 \\
\hline & $\begin{array}{l}\text { Being afraid that something happens with my } \\
\text { parents or someone else in my family }\end{array}$ & 25 & Scary thoughts & 4.2 \\
\hline & $\begin{array}{l}\text { Being afraid that someone will laugh at me or say } \\
\text { something/will be unkind to me the next day }\end{array}$ & 29 & Scary thoughts & 2.4 \\
\hline
\end{tabular}

${ }^{1}$ Idea nr. $=$ The number of the generated idea in this group. This corresponds with the numbers on the concept maps in Appendix A. ${ }^{2}$ Merged into main idea = The overall main idea to which the original idea of this group is assigned. ${ }^{3}$ Mean $=$ mean importance rating on a 5-point Likert scale based on the question: 'Think about your sleep, how much does this affect your sleep?' answered on a 5-point Likert scale from 'does not affect at all $=1^{\prime}$ to 'affects a whole $\operatorname{lot}^{\prime}=5^{\prime}$. Bold values indicate ideas rated as important (with a rating $\geq 3.00$ ); Cursive values indicate the overall mean rating per cluster. 
Table A3. Cluster compositions of original ideas and mean importance ratings of children in group 3A (S1 $N=7$; $22 N=5$ ), including the assignment of original ideas to main ideas.

\begin{tabular}{|c|c|c|c|c|}
\hline Clusters & Original Ideas & Idea nr. ${ }^{1}$ & Merged to Main Idea $^{2}$ & Mean $^{3}$ \\
\hline \multirow[t]{18}{*}{$\begin{array}{l}\text { 1. Being unable or } \\
\text { reluctant to sleep }\end{array}$} & & & & 2.5 \\
\hline & $\begin{array}{l}\text { Thinking and having many different } \\
\text { thoughts }\end{array}$ & 1 & Many thoughts & 3.8 \\
\hline & $\begin{array}{l}\text { watching something on a screen } \\
\text { (computer, phone, TV, tablet, laptop) } \\
\text { shortly before bedtime }\end{array}$ & 2 & Screen use around bedtime & 2.0 \\
\hline & $\begin{array}{l}\text { Wanting to see something on TV, but not } \\
\text { being allowed to see it due to bedtime }\end{array}$ & 3 & Negative affective state & 2.2 \\
\hline & $\begin{array}{l}\text { Messages I receive in the evening via the } \\
\text { group chat on my phone }\end{array}$ & 4 & $\begin{array}{l}\text { Social media use around } \\
\text { bedtime }\end{array}$ & 2.0 \\
\hline & $\begin{array}{l}\text { When my parents are watching TV and } \\
\text { the sound is too loud }\end{array}$ & 6 & Noise inside & 3.2 \\
\hline & My parents making noise in our home ${ }^{4}$ & 7 & Noise inside & 3.0 \\
\hline & $\begin{array}{l}\text { Wanting to declutter my room before I } \\
\text { go to sleep }\end{array}$ & 15 & Distraction in the bedroom & 1.8 \\
\hline & $\begin{array}{l}\text { Not going to bed at the same time every } \\
\text { night }\end{array}$ & 16 & $\begin{array}{l}\text { No consistent sleep } \\
\text { schedule }\end{array}$ & 2.6 \\
\hline & $\begin{array}{l}\text { Going to bed too early and not being } \\
\text { tired enough to fall asleep }\end{array}$ & 17 & Going to bed too early & 3.2 \\
\hline & When I do not do my best to go to sleep & 18 & Reluctant to go to sleep & 2.8 \\
\hline & Not feeling like going to sleep & 19 & Reluctant to go to sleep & 2.5 \\
\hline & Pets making noise in our home & 23 & Noise inside & 1.4 \\
\hline & $\begin{array}{l}\text { When an electronic device in my } \\
\text { bedroom (e-reader, alarm clock) makes } \\
\text { noise }\end{array}$ & 29 & Distraction in the bedroom & 2.4 \\
\hline & Keep reading for too long & 31 & Reluctant to go to sleep & 2.2 \\
\hline & Doing sports late in the evening & 37 & Evening physical activity & 2.4 \\
\hline & $\begin{array}{l}\text { When my brother/sister is allowed to } \\
\text { watch something (TV, film) and I am not }\end{array}$ & 40 & Fear of missing out & 2.0 \\
\hline & $\begin{array}{l}\text { Wanting to finish something that I } \\
\text { started before going to sleep }\end{array}$ & 41 & Reluctant to go to sleep & 3.3 \\
\hline \multirow[t]{3}{*}{$\begin{array}{l}\text { 2. Uncomfortable in } \\
\text { bed }\end{array}$} & & & & 3.2 \\
\hline & $\begin{array}{l}\text { Not having the right pillow and } \\
\text { therefore not being able to lie down } \\
\text { comfortably }\end{array}$ & 5 & $\begin{array}{l}\text { Uncomfortable sleeping } \\
\text { materials }\end{array}$ & 3.2 \\
\hline & Not being able to lie down comfortably & 30 & $\begin{array}{l}\text { Unable to lie down } \\
\text { comfortably }\end{array}$ & 3.2 \\
\hline \multirow{7}{*}{$\begin{array}{l}\text { 3. Illness and } \\
\text { discomfort }\end{array}$} & & & & 2.9 \\
\hline & $\begin{array}{l}\text { Having difficulty breathing due to } \\
\text { hypersensitivity to dust in my bedroom }\end{array}$ & 13 & Illness & 2.6 \\
\hline & Feeling cold in my bed & 14 & Not the right temperature & 2.4 \\
\hline & Feeling hot in my bed & 20 & Not the right temperature & 3.6 \\
\hline & Being sick and not feeling well & 21 & Illness & 3.3 \\
\hline & $\begin{array}{l}\text { Having a cold and being unable to } \\
\text { breath properly }\end{array}$ & 22 & Illness & 2.8 \\
\hline & Having a dry throat & 35 & Illness & 2.8 \\
\hline
\end{tabular}


Table A3. Cont.

\begin{tabular}{|c|c|c|c|c|}
\hline Clusters & Original Ideas & Idea nr. ${ }^{1}$ & Merged to Main Idea $^{2}$ & Mean $^{3}$ \\
\hline \multirow[t]{17}{*}{$\begin{array}{l}\text { 4. Stressful and exciting } \\
\text { thoughts and feelings }\end{array}$} & & & & 2.9 \\
\hline & Feeling sad & 8 & Negative affective state & 3.4 \\
\hline & Being angry & 9 & Negative affective state & 3.2 \\
\hline & Being afraid & 10 & Negative affective state & 2.8 \\
\hline & Being irritated & 11 & Negative affective state & 2.8 \\
\hline & Feeling restless & 12 & Negative affective state & 2.8 \\
\hline & Nightmares and bad dreams & 24 & Nightmares & 3.2 \\
\hline & Thinking about bad things 5 & 25 & Recent stressful event & 3.0 \\
\hline & $\begin{array}{l}\text { Missing my dad or mum when they are } \\
\text { not at home }\end{array}$ & 26 & Negative affective state & 3.2 \\
\hline & Feeling alone when I am in bed ${ }^{5}$ & 27 & Negative affective state & 2.8 \\
\hline & $\begin{array}{l}\text { Hearing weird or scary sounds during } \\
\text { the night } b\end{array}$ & 28 & Scary sounds & 2.6 \\
\hline & $\begin{array}{l}\text { Being afraid something scary will } \\
\text { happen in my bedroom }\end{array}$ & 32 & Scary thoughts & 3.4 \\
\hline & Looking forward to something fun & 33 & Excitement & 3.0 \\
\hline & $\begin{array}{l}\text { When I need to pee, but I am too afraid } \\
\text { to go to the toilet }\end{array}$ & 34 & Scary thoughts & 2.4 \\
\hline & $\begin{array}{l}\text { Things in my room that suddenly fall } \\
\text { down or topples } b\end{array}$ & 36 & $\begin{array}{l}\text { Scared by something in the } \\
\text { bedroom }\end{array}$ & 3.4 \\
\hline & $\begin{array}{l}\text { When my parents do not pay attention } \\
\text { to me because they are busy with my } \\
\text { brother or sister } 5\end{array}$ & 38 & $\begin{array}{l}\text { Lacks attention from } \\
\text { parents }\end{array}$ & 1.8 \\
\hline & $\begin{array}{l}\text { Getting angry because my brother or } \\
\text { sister makes noise }\end{array}$ & 39 & Negative affective state & 2.0 \\
\hline
\end{tabular}

\footnotetext{
${ }^{1}$ Idea nr. $=$ The number of the generated idea in this group. This corresponds with the numbers on the concept maps in Appendix A. ${ }^{2}$ Merged into main idea $=$ The overall main idea to which the original idea of this group is assigned. ${ }^{3}$ Mean $=$ mean importance rating on a 5-point Likert scale based on the question: 'Think about your sleep, how much does this affect your sleep?' answered on a 5-point Likert scale from 'does not affect at all $=1$ ' to 'affects a whole lot' $=5^{\prime} ;{ }^{4}$ idea was moved to cluster $1 ;{ }^{5}$ idea was moved to cluster 4 . Bold values indicate ideas rated as important (with a rating $\geq 3.00$ ); Cursive values indicate the overall mean rating per cluster. $\mathrm{S} 1=$ Session 1 , brainstorm; S2 = Session 2, sort and rate.
} 
Table A4. Cluster compositions of original ideas and mean importance ratings of children in group 3B (S1 $N=7$; $22 N=8$ ), including the assignment of original ideas to main ideas.

\begin{tabular}{|c|c|c|c|c|}
\hline Clusters & Original Ideas & Idea nr. $^{1}$ & Merged to Main Idea ${ }^{2}$ & Mean $^{3}$ \\
\hline \multirow{12}{*}{$\begin{array}{l}\text { 1. Stressful and exciting } \\
\text { thoughts and feelings }\end{array}$} & & & & 3.1 \\
\hline & $\begin{array}{l}\text { Looking forward to something that will happen the } \\
\text { next day }\end{array}$ & 1 & Excitement & 3.4 \\
\hline & Thinking and having many thoughts & 2 & Many thoughts & 4.3 \\
\hline & $\begin{array}{l}\text { Being nervous for something that is going to } \\
\text { happen }\end{array}$ & 3 & Upcoming stressful event & 2.9 \\
\hline & Thinking about which secondary school I will go to & 4 & Upcoming stressful event & 2.5 \\
\hline & Thinking about my parents, who were in a fight & 8 & Stressful family situation & 2.4 \\
\hline & $\begin{array}{l}\text { Thinking about my share in a fight at school and } \\
\text { how I could do things better next time }\end{array}$ & 9 & Recent stressful event & 2.5 \\
\hline & $\begin{array}{l}\text { Being enthusiastic about something that happened } \\
\text { that day }\end{array}$ & 11 & Excitement & 2.9 \\
\hline & Thinking about not being able to sleep well & 23 & Upcoming stressful event & 2.8 \\
\hline & Thinking about the divorce of my parents & 24 & Stressful family situation & 2.0 \\
\hline & $\begin{array}{l}\text { Being bullied and thinking about this when I am in } \\
\text { bed }\end{array}$ & 28 & Recent stressful event & 2.5 \\
\hline & When something stressful is going to happen & 29 & Upcoming stressful event & 3.6 \\
\hline \multirow{9}{*}{$\begin{array}{l}\text { 2. Noise and distractions in } \\
\text { the bedroom }\end{array}$} & & & & 2.3 \\
\hline & $\begin{array}{l}\text { When someone in our home is watching TV and the } \\
\text { sound is too loud }\end{array}$ & 13 & Noise inside & 2.4 \\
\hline & $\begin{array}{l}\text { Noise from a brother or sister with whom I share } \\
\text { the same room }\end{array}$ & 20 & Distractions in the bedroom & 1.9 \\
\hline & Noise from the street & 31 & Noise outside & 2.4 \\
\hline & Noise inside our house & 32 & Noise inside & 2.5 \\
\hline & $\begin{array}{l}\text { When my phone beeps at night due to games or } \\
\text { messages }\end{array}$ & 42 & Distractions in the bedroom & 1.5 \\
\hline & The buzzing and stinging of mosquitos & 45 & Distractions in the bedroom & 3.3 \\
\hline & $\begin{array}{l}\text { Not feeling comfortable because of people } \\
\text { screaming outside }\end{array}$ & 46 & Feeling unsafe & 2.3 \\
\hline & Ticking of the clock in my bedroom & 48 & Distractions in the bedroom & 2.1 \\
\hline \multirow{8}{*}{ 3. Illness and discomfort } & Illness and not feeling well & 7 & Illness & 3.5 \\
\hline & Not being able to lie down comfortably in my bed & 10 & Unable to lie down comfortably & 2.4 \\
\hline & Having had too much to eat & 14 & Inadequate dietary behaviour & 2.3 \\
\hline & Urgently needing to pee & 22 & Needing to pee & 2.6 \\
\hline & Feeling too cold in bed & 25 & Not the right temperature & 2.9 \\
\hline & Feeling too hot in bed & 26 & Not the right temperature & 2.6 \\
\hline & Feeling pain & 39 & Pain & 2.5 \\
\hline & Being thirsty & 41 & Inadequate dietary behaviour & 2.3 \\
\hline \multirow[t]{6}{*}{ 4. Emotions } & & & & 2.6 \\
\hline & Nightmares & 30 & Nightmares & 2.8 \\
\hline & Being afraid & 36 & Being afraid & 2.6 \\
\hline & Being very happy & 37 & Excitement & 2.9 \\
\hline & Being angry & 38 & Negative affective state & 2.4 \\
\hline & Being afraid that someone comes into my home & 44 & Being afraid & 2.1 \\
\hline \multirow{16}{*}{ 5. Unable or reluctant to sleep } & & & & 2.2 \\
\hline & $\begin{array}{l}\text { Having had too little exercise during the day and } \\
\text { therefore too much energy in the evening }\end{array}$ & 5 & $\begin{array}{l}\text { Inadequate amount of daytime } \\
\text { physical activity }\end{array}$ & 2.5 \\
\hline & $\begin{array}{l}\text { When my pet comes into my bedroom and distracts } \\
\text { me when I am in bed }\end{array}$ & 6 & Distractions in the bedroom & 1.5 \\
\hline & $\begin{array}{l}\text { Watching a scary movie and continuing to think } \\
\text { about it }{ }^{4}\end{array}$ & 12 & Watching/reading something scary & 2.6 \\
\hline & Having had too little too eat and feeling hungry ${ }^{4}$ & 15 & Inadequate dietary behaviour & 2.6 \\
\hline & Being too tired because I did a lot & 17 & Excessive daytime stimulation & 1.9 \\
\hline & Not feeling like going to sleep ${ }^{4}$ & 18 & Reluctant to go to sleep & 2.4 \\
\hline & Going to bed too early and not being tired & 19 & Going to bed too early & 3.6 \\
\hline & $\begin{array}{l}\text { Going to bed too late and not feeling sleepy any } \\
\text { more }\end{array}$ & 21 & No consistent sleep schedule & 2.3 \\
\hline & Watching TV right before going to sleep & 33 & Screen use around bedtime & 2.0 \\
\hline & Playing computer games right before going to sleep & 34 & $\begin{array}{l}\text { Playing active games before } \\
\text { bedtime }\end{array}$ & 2.0 \\
\hline & $\begin{array}{l}\text { Using a screen with blue light (TV, computer, } \\
\text { laptop, tablet) right before going to sleep }\end{array}$ & 35 & Screen use around bedtime & 2.3 \\
\hline & $\begin{array}{l}\text { Being really tired and getting activated when I } \\
\text { brush my teeth }\end{array}$ & 40 & No consistent sleep schedule & 1.8 \\
\hline & Scary sounds ${ }^{4}$ & 43 & Scary sounds & 2.4 \\
\hline & Too much light in my bedroom & 47 & Too light & 2.4 \\
\hline & $\begin{array}{l}\text { Lying in my mother's bed and looking out the } \\
\text { window } 4\end{array}$ & 49 & Distractions in the bedroom & 1.5 \\
\hline \multirow{3}{*}{$\begin{array}{l}\text { 6. General negative state of } \\
\text { mind }\end{array}$} & & & & 2.5 \\
\hline & $\begin{array}{l}\text { When I feel gloomy and not in the mood to do } \\
\text { anything }\end{array}$ & 16 & Negative affective state & 2.6 \\
\hline & Feeling insecure about myself & 27 & Negative affective state & 2.4 \\
\hline
\end{tabular}

${ }^{1}$ Idea nr. = The number of the generated idea in this group. This corresponds with the numbers on the concept maps in Appendix A. ${ }^{2}$ Merged into main idea $=$ The overall main idea to which the original idea of this group is assigned. ${ }^{3}$ Mean $=$ mean importance rating on a 5-point Likert scale based on the question: 'Think about your sleep, how much does this affect your sleep?' answered on a 5-point Likert scale from 'does not affect at all $=1$ ' to 'affects a whole $\operatorname{lot}^{\prime}=5^{\prime} ;{ }^{4}$ idea was moved to cluster 5 . Bold values indicate ideas rated as important (with a rating $\geq 3.00$ ); Cursive values indicate the overall mean rating per cluster. S1 = Session 1, brainstorm; $\mathrm{S} 2=$ Session 2, sort and rate. 
Table A5. Cluster compositions of original ideas and mean importance ratings of children in group 4A $(N=7)$, including the assignment of original ideas to main ideas.

\begin{tabular}{|c|c|c|c|c|}
\hline Clusters & Original Ideas & Idea nr. ${ }^{1}$ & Merged to Main Idea ${ }^{2}$ & Mean $^{3}$ \\
\hline \multirow{8}{*}{$\begin{array}{l}\text { 1. Stressful thoughts and } \\
\text { feelings }\end{array}$} & & & & 2.2 \\
\hline & $\begin{array}{l}\text { When I had a fight with classmates and the fight } \\
\text { has not been resolved yet }\end{array}$ & 1 & Recent stressful event & 2.0 \\
\hline & $\begin{array}{l}\text { Being bullied and thinking about it when I am in } \\
\text { bed }\end{array}$ & 5 & Recent stressful event & 2.6 \\
\hline & $\begin{array}{l}\text { Being in a fight with my father, mother, brother or } \\
\text { sister and thinking about it when I am in bed }\end{array}$ & 22 & Recent stressful event & 3.1 \\
\hline & $\begin{array}{l}\text { Thinking about being kicked out of class at school } \\
\text { by my teacher }\end{array}$ & 27 & Recent stressful event & 1.7 \\
\hline & Being hurt by a classmate & 32 & Recent stressful event & 2.0 \\
\hline & Not having had a nice day & 43 & Recent stressful event & 2.4 \\
\hline & Receiving unpleasant messages on social media & 45 & Recent stressful event & 1.6 \\
\hline \multirow{10}{*}{$\begin{array}{l}\text { 2. Noise, distractions, and } \\
\text { stressful family situation }\end{array}$} & & & & 2.9 \\
\hline & $\begin{array}{l}\text { When my parents make too much noise in our } \\
\text { home }\end{array}$ & 3 & Noise inside & 3.9 \\
\hline & Screaming noise from the neighbours & 13 & Noise outside & 2.9 \\
\hline & Noise from outside & 16 & Noise outside & 3.0 \\
\hline & When my parents are fighting and screaming & 17 & Stressful family situation & 3.4 \\
\hline & $\begin{array}{l}\text { The sound of whizzing in my ears when it is very } \\
\text { quiet } 4\end{array}$ & 21 & Distractions in the bedroom & 2.1 \\
\hline & Feeling sad & 29 & Negative affective state & 2.9 \\
\hline & $\begin{array}{l}\text { When I hear my father and mother doing dirty } \\
\text { things }\end{array}$ & 35 & Noise inside & 2.7 \\
\hline & A brother or sister that keeps me awake & 41 & Distractions in the bedroom & 2.9 \\
\hline & The sound of the TV is too loud when I am in bed 5 & 42 & Noise inside & 2.9 \\
\hline \multirow[t]{12}{*}{ 3. Unable or reluctant to sleep } & & & & 2.7 \\
\hline & $\begin{array}{l}\text { Being nervous for the next day, because something } \\
\text { fun is going to happen }\end{array}$ & 4 & Excitement & 3.3 \\
\hline & When I go to bed too early and I am not tired yet & 7 & Going to bed too early & 3.3 \\
\hline & Doing sports until late & 8 & Evening physical activity & 1.9 \\
\hline & Going to bed very late & 10 & No consistent sleep schedule & 1.9 \\
\hline & $\begin{array}{l}\text { Having slept during the day and therefore not } \\
\text { feeling tired at night }\end{array}$ & 18 & Daytime nap & 2.7 \\
\hline & Feeling restless & 20 & Negative affective state & 3.1 \\
\hline & Feeling too hot & 24 & Not the right temperature & 3.6 \\
\hline & Still feeling like playing ${ }^{6}$ & 26 & Reluctant to go to sleep & 3.0 \\
\hline & Still having too much energy & 37 & Not tired & 3.1 \\
\hline & Using my phone right before going to sleep & 44 & Screen use around bedtime & 2.1 \\
\hline & Secretly using the tablet after bedtime & 46 & Screen use around bedtime & 1.7 \\
\hline \multirow{4}{*}{$\begin{array}{l}\text { 4. Stressed for the upcoming } \\
\text { day }\end{array}$} & & & & 3.5 \\
\hline & $\begin{array}{l}\text { When there are important and stressful events } \\
\text { planned }\end{array}$ & 31 & Upcoming stressful event & 3.0 \\
\hline & Going to do something stressful the next day & 33 & Upcoming stressful event & 4.2 \\
\hline & $\begin{array}{l}\text { Needing to do something I do not want to do the } \\
\text { next day }\end{array}$ & 34 & Upcoming stressful event & 3.3 \\
\hline \multirow[t]{9}{*}{ 5. Discomfort } & & & & 3.1 \\
\hline & Late dinner & 9 & Inadequate dietary behaviour & 2.0 \\
\hline & Needing to pee when I am already in bed ${ }^{7}$ & 11 & Needing to pee & 2.7 \\
\hline & Having had too much to eat & 14 & Inadequate dietary behaviour & 2.7 \\
\hline & Having had too many different things to eat & 15 & Inadequate dietary behaviour & 2.6 \\
\hline & Not feeling well & 19 & Illness & 3.9 \\
\hline & Feeling hungry & 23 & Inadequate dietary behaviour & 3.6 \\
\hline & Muscle strain & 36 & Pain & 3.7 \\
\hline & Feeling pain & 39 & Pain & 3.4 \\
\hline \multirow[t]{9}{*}{ 6. Being afraid } & & & & 2.7 \\
\hline & $\begin{array}{l}\text { Being afraid because of scary things that my father } \\
\text { or mother told me }\end{array}$ & 2 & Being afraid & 2.6 \\
\hline & $\begin{array}{l}\text { In bed, thinking about something scary that I } \\
\text { experienced }\end{array}$ & 6 & Recent scary event & 3.7 \\
\hline & $\begin{array}{l}\text { Having seen something scary on TV before going to } \\
\text { bed }\end{array}$ & 12 & Watching/reading something scary & 3.0 \\
\hline & Having seen something scary at daytime & 25 & Recent scary event & 2.4 \\
\hline & Having seen a scary movie & 28 & Watching/reading something scary & 3.1 \\
\hline & Not feeling safe & 30 & Feeling unsafe & 2.2 \\
\hline & Having a nightmare & 38 & Nightmares & 3.0 \\
\hline & $\begin{array}{l}\text { Being afraid in the dark and preferring a light in my } \\
\text { room }\end{array}$ & 40 & Being afraid & 1.6 \\
\hline
\end{tabular}

${ }^{1}$ Idea nr. $=$ The number of the generated idea in this group. This corresponds with the numbers on the concept maps in Appendix A. ${ }^{2}$ Merged into main idea $=$ The overall main idea to which the original idea of this group is assigned. ${ }^{3}$ Mean $=$ mean importance rating on a 5-point Likert scale based on the question: 'Think about your sleep, how much does this affect your sleep?' answered on a 5-point Likert scale from 'does not affect at all $=1$ ' to 'affects a whole $\operatorname{lot}^{\prime}=55^{\prime} ;{ }^{4}$ idea was moved to cluster $2 ;{ }^{5}$ idea was moved from cluster 1 to cluster $2 ;{ }^{6}$ idea was moved to from cluster 4 to cluster $3 ;{ }^{7}$ idea was moved to from cluster 2 to cluster 5 . Bold values indicate ideas rated as important (with a rating $\geq 3.00$ ); Cursive values indicate the overall mean rating per cluster. 
Table A6. Cluster compositions of original ideas and mean importance ratings of children in group 4B (S1 $N=7 ; \mathrm{S} 2 N=9$ ), including the assignment of original ideas to main ideas.

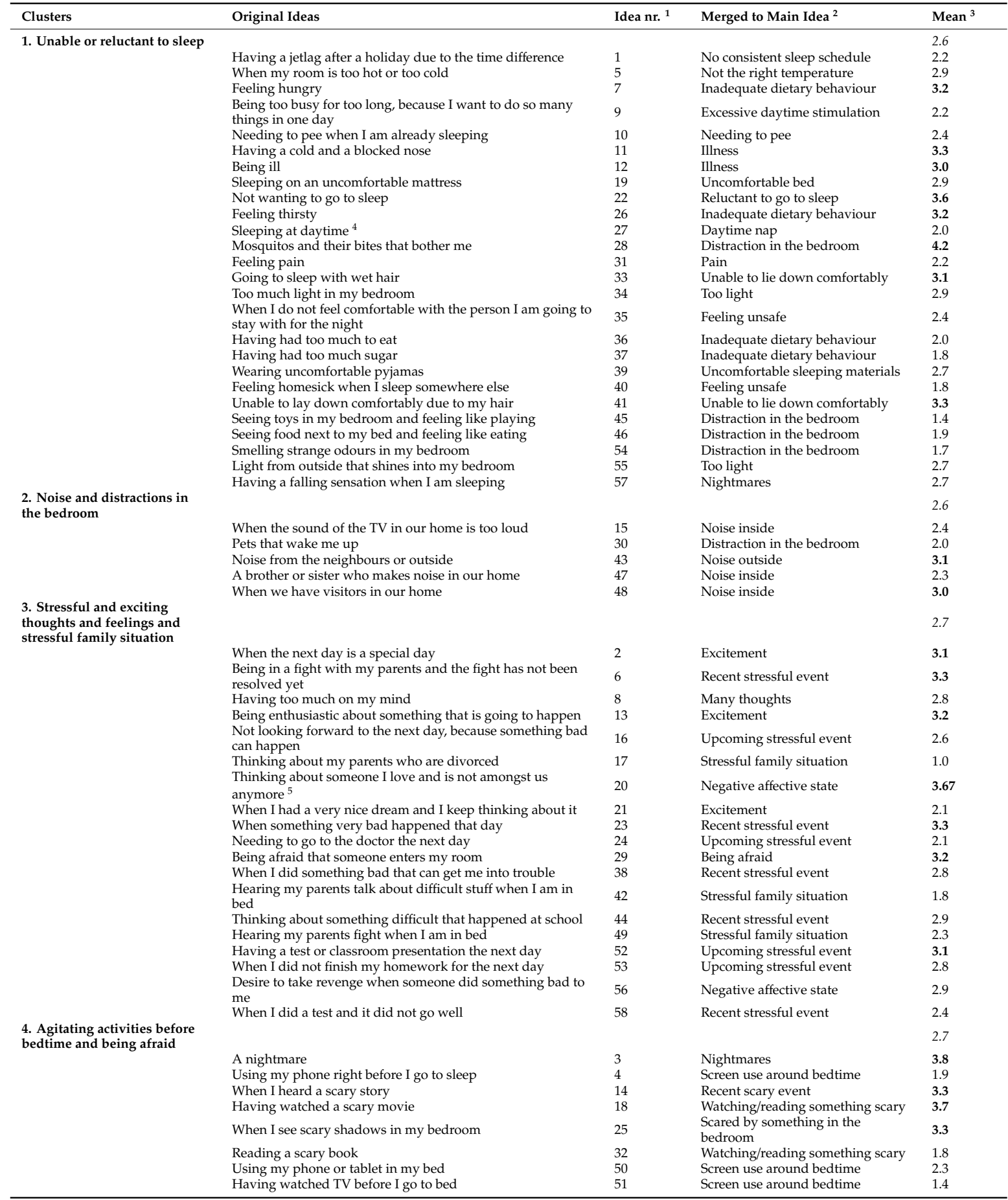

${ }^{1}$ Idea nr. $=$ The number of the generated idea in this group. This corresponds with the numbers on the concept maps in Appendix A. ${ }^{2}$ Merged into main idea = The overall main idea to which the original idea of this group is assigned. ${ }^{3}$ Mean $=$ mean importance rating on a 5-point Likert scale based on the question: "Think about your sleep, how much does this affect your sleep?' answered on a 5-point Likert scale from 'does not affect at all $=1$ ' to 'affects a whole lot' $=5^{\prime} ;{ }^{4}$ idea was moved from cluster 2 to cluster $1 ;{ }^{5}$ idea was moved from cluster 2 to cluster 3 . Bold values indicate ideas rated as important (with a rating $\geq 3.00$ ); Cursive values indicate the overall mean rating per cluster. S1 = Session 1, brainstorm; S2 = Session 2, sort and rate. 
Table A7. Cluster compositions of original ideas and mean importance ratings of parents in group 1 (S1 $N=4$; $22 N=7$ ), including the assignment of original ideas to main ideas.

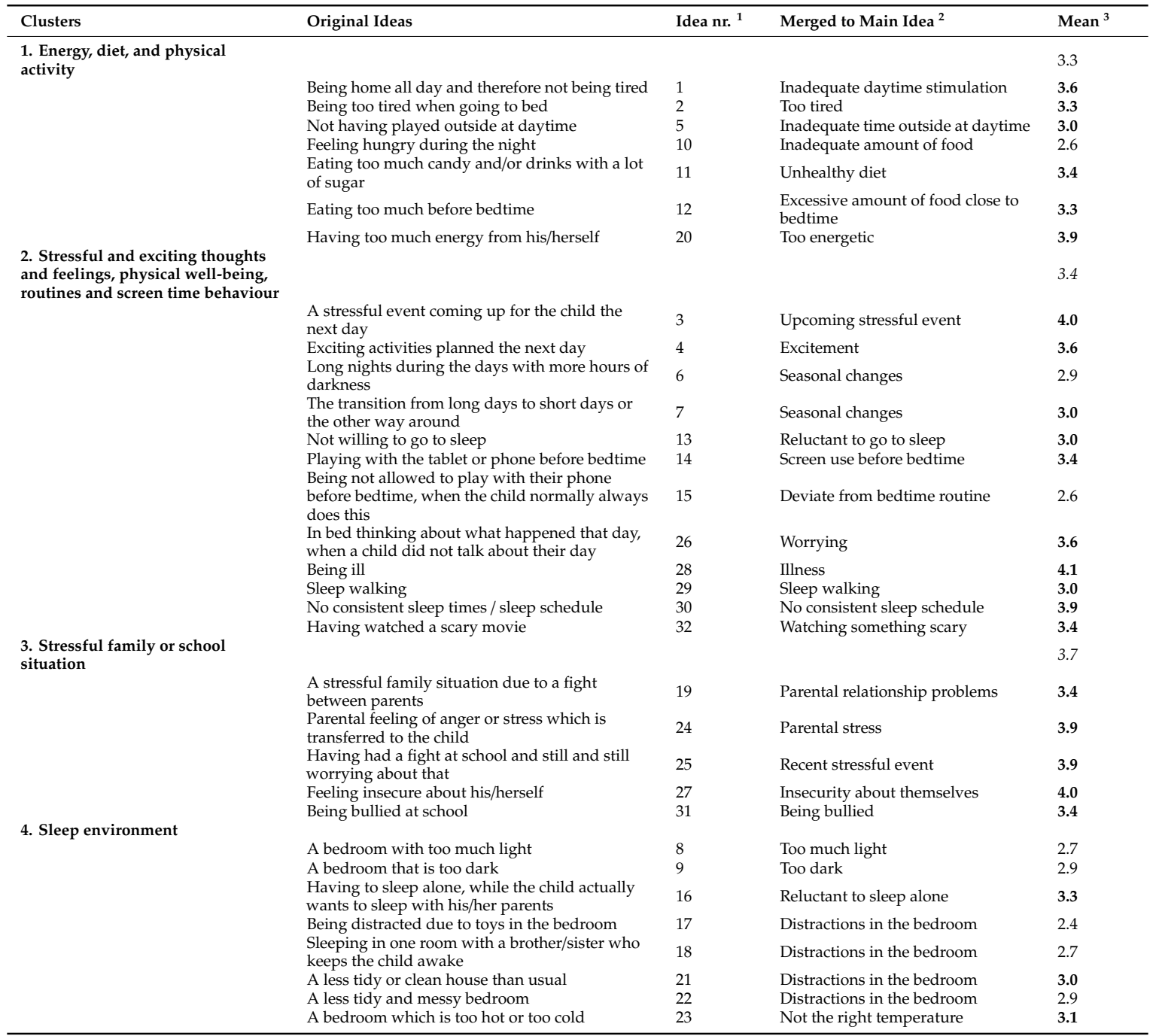

${ }^{1}$ Idea nr. = The number of the generated idea in this group. This corresponds with the numbers on the concept maps in Appendix A. ${ }^{2}$ Merged into main idea = The overall main idea to which the original idea of this group is assigned. ${ }^{3}$ Mean $=$ mean importance rating on a 5-point Likert scale based on the question: "Think about the sleep of a child in the age of 4-12 years, how much does this affect their sleep?' answered on a 5-point Likert scale from 'does not affect at all $=1$ ' to 'affects a whole lot $=5^{\prime}$. Bold values indicate ideas rated as important (with a rating 23.00); Cursive values indicate the overall mean rating per cluster. S1 = Session 1, brainstorm; S2 = Session 2, sort and rate. 
Table A8. Cluster compositions of original ideas and mean importance ratings of parents in group 2 (S1 $N=8$; S2 $N=9$ ), including the assignment of original ideas to main ideas.

\begin{tabular}{|c|c|c|c|c|}
\hline Clusters & Original Ideas & Idea nr. ${ }^{1}$ & Merged to Main Idea $^{2}$ & Mean $^{3}$ \\
\hline \multirow{12}{*}{$\begin{array}{l}\text { 1. Diet, physical activity, and } \\
\text { screen behaviour }\end{array}$} & & & & 3.5 \\
\hline & Having had too much sugar & 1 & Unhealthy diet & 3.7 \\
\hline & Having watched a scary movie & 8 & Watching something scary & 4.0 \\
\hline & $\begin{array}{l}\text { Inadequate amount of physical activity during the day } \\
\text { and therefore not being tired }\end{array}$ & 9 & $\begin{array}{l}\text { Inadequate amount of daytime } \\
\text { physical activity }\end{array}$ & 3.6 \\
\hline & Using the TV before bedtime & 13 & Screen use before bedtime & 3.1 \\
\hline & Using a phone before bedtime & 14 & Screen use before bedtime & 3.2 \\
\hline & Using the computer before bedtime & 15 & Screen use before bedtime & 3.3 \\
\hline & Using a tablet before bedtime & 16 & Screen use before bedtime & 3.3 \\
\hline & Late dinner & 21 & $\begin{array}{l}\text { Excessive amount of food close to } \\
\text { bedtime }\end{array}$ & 3.4 \\
\hline & Having had too much to eat right before going to bed & 22 & $\begin{array}{l}\text { Excessive amount of food close to } \\
\text { bedtime }\end{array}$ & 3.6 \\
\hline & Unhealthy diet during the day & 23 & Unhealthy diet & 3.6 \\
\hline & $\begin{array}{l}\text { Before bedtime, playing with toys with a lot of light and } \\
\text { noise }\end{array}$ & 42 & $\begin{array}{l}\text { Play with activating toys before } \\
\text { bedtime }\end{array}$ & 3.1 \\
\hline \multirow[t]{4}{*}{ 2. Noise from the neighbours } & & & & 3.6 \\
\hline & Screaming kids from the neighbours & 39 & Noise outside & 3.7 \\
\hline & Fighting neighbours & 40 & Noise outside & 3.8 \\
\hline & Noise from the neighbours' pets & 41 & Noise outside & 3.2 \\
\hline \multirow[t]{19}{*}{$\begin{array}{l}\text { 3. Mental distress, physical } \\
\text { well-being, and stressful family } \\
\text { situation }\end{array}$} & & & & \\
\hline & $\begin{array}{l}\text { Absence of the mother or father when the child needs } \\
\text { attention }\end{array}$ & 2 & $\begin{array}{l}\text { Parental absence when child needs } \\
\text { attention }\end{array}$ & 4.0 \\
\hline & A stressful event coming up for the child the next day & 3 & Upcoming stressful event & 3.9 \\
\hline & An important event coming up for the child the next day & 4 & Upcoming stressful event & 3.8 \\
\hline & Being ill & 5 & Illness & 4.22 \\
\hline & Not being able to breathe well due to a cold & 6 & Illness & 4.2 \\
\hline & $\begin{array}{l}\text { Having had a fight at school and still worrying about } \\
\text { that }\end{array}$ & 10 & Recent stressful event & 3.2 \\
\hline & $\begin{array}{l}\text { Worrying about something and not being able to share } \\
\text { this }\end{array}$ & 20 & Worrying & 3.3 \\
\hline & Home visits from family or friends & 27 & Fear of missing out & 3.9 \\
\hline & Something fun coming up the next day & 43 & Excitement & 3.6 \\
\hline & $\begin{array}{l}\text { Financial problems at home, causing that the parent is } \\
\text { not able to buy everything for the child }\end{array}$ & 44 & Financial family problems & 2.6 \\
\hline & Having nothing to look forward to the next day & 46 & Worrying & 2.6 \\
\hline & Having done something naughty at daytime & 47 & Recent stressful event & 2.6 \\
\hline & Being bullied & 48 & Being bullied & 3.8 \\
\hline & Parents going through a divorce & 49 & Parental relationship problems & 3.8 \\
\hline & Parents who are fighting & 50 & Parental relationship problems & 4.1 \\
\hline & Being jealous of a friend or classmate & 51 & Worrying & 2.9 \\
\hline & Parents who do not live together any more & 52 & Parental relationship problems & 3.4 \\
\hline & Being afraid when lying in bed & 53 & Being afraid & 3.6 \\
\hline \multirow{8}{*}{$\begin{array}{l}\text { 4. Routines and social } \\
\text { environment }\end{array}$} & & & & 3.5 \\
\hline & $\begin{array}{l}\text { Having a longer night sleep than usual the night before, } \\
\text { because the child woke up later }\end{array}$ & 7 & No consistent sleep schedule & 4.00 \\
\hline & Irregular sleep times during weekends & 11 & No consistent sleep schedule & 3.1 \\
\hline & Not indicating clearly when the child needs to go to bed & 17 & Indistinctness about bedtime & 3.2 \\
\hline & The change of the time due to summer and wintertime & 24 & No consistent sleep schedule & 3.7 \\
\hline & Holidays or having a free day the next day & 32 & No consistent sleep schedule & 3.2 \\
\hline & A brother or sister that is allowed to go to bed later & 33 & $\begin{array}{l}\text { Social norm for bedtime among } \\
\text { siblings }\end{array}$ & 4.2 \\
\hline & Classmates that have a later bedtime & 34 & $\begin{array}{l}\text { Social norm for bedtime among } \\
\text { classmates }\end{array}$ & 2.8 \\
\hline \multirow{14}{*}{$\begin{array}{l}\text { 5. Sleep environment and } \\
\text { bedtime routine }\end{array}$} & & & & 3.1 \\
\hline & $\begin{array}{l}\text { Not reading a story to the child, when this normally } \\
\text { does happen }\end{array}$ & 12 & $\begin{array}{l}\text { Deviate from usual bedtime } \\
\text { routine }\end{array}$ & 2.7 \\
\hline & Not having a bedtime routine & 18 & No bedtime routine & 3.3 \\
\hline & Having napped in the afternoon & 19 & Daytime nap & 3.0 \\
\hline & When it is still light outside when they need to go to bed & 25 & Seasonal changes & 4.0 \\
\hline & Sleeping at a different place than his/her own bed & 26 & Different sleep environment & 3.0 \\
\hline & $\begin{array}{l}\text { Not having a comfortable bed and therefore not being } \\
\text { able to lie down comfortably }\end{array}$ & 28 & Uncomfortable place to sleep & 3.0 \\
\hline & A bedroom that is too hot or too cold & 29 & Not the right temperature & 3.4 \\
\hline & $\begin{array}{l}\text { Uncomfortable sleeping attributes, such as pillows, } \\
\text { pyjamas, underwear }\end{array}$ & 30 & Uncomfortable sleeping material & 3.1 \\
\hline & $\begin{array}{l}\text { The absence of the favourite stuffed animal or sleeping } \\
\text { cloth }\end{array}$ & 31 & $\begin{array}{l}\text { Absence of favourite sleep } \\
\text { accessory }\end{array}$ & 2.7 \\
\hline & Too much light in the bedroom & 35 & Too much light & 3.4 \\
\hline & A bedroom that is too dark & 36 & Too dark & 2.9 \\
\hline & Busy decor in the bedroom & 37 & Distractions in the bedroom & 3.0 \\
\hline & No fresh air in the bedroom & 38 & No fresh air & 3.0 \\
\hline
\end{tabular}

${ }^{1}$ Idea nr. $=$ The number of the generated idea in this group. This corresponds with the numbers on the concept maps in Appendix A. ${ }^{2}$ Merged into main idea $=$ The overall main idea to which the original idea of this group is assigned. ${ }^{3}$ Mean $=$ mean importance rating on a 5-point Likert scale based on the question: 'Think about the sleep of a child in the age of 4-12 years, how much does this affect their sleep?' answered on a 5-point Likert scale from 'does not affect at all $=1$ ' to 'affects a whole lot $=5$ '. Bold values indicate ideas rated as important (with a rating $\geq 3.00$ ); Cursive values indicate the overall mean rating per cluster. $\mathrm{S} 1$ = Session 1, brainstorm; $\mathrm{S} 2=$ Session 2, sort and rate. 
Table A9. Cluster compositions of original ideas and mean importance ratings of parents in group 3 (S1 $N=8$; S2 $N=9$ ), including the assignment of original ideas to main ideas.

\begin{tabular}{|c|c|c|c|c|}
\hline Clusters & Original Ideas & Idea nr. ${ }^{1}$ & Merged to Main Idea ${ }^{2}$ & Mean $^{3}$ \\
\hline \multirow{13}{*}{$\begin{array}{l}\text { 1. Mental distress and active } \\
\text { brain }\end{array}$} & & & & 3.4 \\
\hline & Having many thoughts & 1 & Many thoughts & 4.2 \\
\hline & Having all kinds of questions before bedtime & 2 & Many thoughts & 3.0 \\
\hline & Wanting to solve world problems before bedtime & 3 & Many thoughts & 3.9 \\
\hline & $\begin{array}{l}\text { Continuing to think about something that is about to } \\
\text { happen the next day }\end{array}$ & 4 & Upcoming stressful event & 3.6 \\
\hline & $\begin{array}{l}\text { Continuing to think about something that happened } \\
\text { that day }\end{array}$ & 5 & Recent stressful event & 3.6 \\
\hline & $\begin{array}{l}\text { Having many ideas and wanting to realize these before } \\
\text { going to sleep }\end{array}$ & 6 & Many thoughts & 3.8 \\
\hline & $\begin{array}{l}\text { Indistinctness about what is going to happen the next } \\
\text { day }\end{array}$ & 7 & Many thoughts & 3.4 \\
\hline & $\begin{array}{l}\text { Being too tired (overtired) before bedtime and getting } \\
\text { hyperactive due to that }\end{array}$ & 10 & Too tired & 3.6 \\
\hline & $\begin{array}{l}\text { When the child has planned to do something that day } \\
\text { and tis still needs to happen before going to bed }\end{array}$ & 18 & Many thoughts & 3.1 \\
\hline & Not willing to end the day, because it was such a fun day & 24 & Many thoughts & 2.6 \\
\hline & $\begin{array}{l}\text { Curiosity about how sleep works, wondering when and } \\
\text { if you will wake up }\end{array}$ & 28 & Many thoughts & 2.0 \\
\hline & $\begin{array}{l}\text { Not being able to let go of feelings of injustice before } \\
\text { bedtime }\end{array}$ & 42 & Many thoughts & 3.7 \\
\hline \multirow{9}{*}{$\begin{array}{l}\text { 2. Family- and social } \\
\text { environment }\end{array}$} & & & & 3.1 \\
\hline & When the parent rushes to take the child to bed & 8 & Parental stress & 3.1 \\
\hline & $\begin{array}{l}\text { When the parent deviates from the usual bedtime } \\
\text { routine }\end{array}$ & 9 & $\begin{array}{l}\text { Deviate from usual bedtime } \\
\text { routine }\end{array}$ & 3.4 \\
\hline & Going to bed too late & 19 & No consistent sleep schedule & 3.3 \\
\hline & When the sleep schedule gets disturbed & 20 & No consistent sleep schedule & 3.4 \\
\hline & $\begin{array}{l}\text { Older brothers or sisters that are allowed to stay up } \\
\text { longer }\end{array}$ & 21 & $\begin{array}{l}\text { Social norm for bedtime among } \\
\text { siblings }\end{array}$ & 2.7 \\
\hline & $\begin{array}{l}\text { Other children in their class that are allowed to stay up } \\
\text { longer }\end{array}$ & 22 & $\begin{array}{l}\text { Social norm for bedtime among } \\
\text { classmates }\end{array}$ & 2.3 \\
\hline & When there are visitors at home & 23 & Fear of missing out & 3.1 \\
\hline & $\begin{array}{l}\text { Wanting to stay with their parent and not wanting to be } \\
\text { alone }\end{array}$ & 33 & Reluctant to sleep alone & 3.2 \\
\hline \multirow[t]{6}{*}{ 3. Sleep environment } & & & & 2.8 \\
\hline & Noise from the street & 11 & Noise outside & 2.9 \\
\hline & Absence of the favourite stuffed animal or sleeping cloth & 29 & $\begin{array}{l}\text { Absence of favourite sleep } \\
\text { accessory }\end{array}$ & 3.1 \\
\hline & A dark bedroom & 32 & Too dark & 2.9 \\
\hline & When it is too quiet at home & 38 & Too quiet & 2.1 \\
\hline & $\begin{array}{l}\text { Noises from in or outside the house that are different } \\
\text { than usual }\end{array}$ & 39 & Noise outside & 3.0 \\
\hline \multirow{9}{*}{$\begin{array}{l}\text { 4. Stressful family situation, } \\
\text { worries and fear }\end{array}$} & & & & 3.9 \\
\hline & Parents who are in a fight & 12 & Parental relationship problems & 4.7 \\
\hline & Relationship problems between parents & 13 & Parental relationship problems & 4.3 \\
\hline & Worrying about things that are going on at home & 14 & Worrying & 3.8 \\
\hline & When something is going on with (one of) their friends & 15 & Worrying & 3.6 \\
\hline & $\begin{array}{l}\text { Not feeling safe at home, in the classroom or outside on } \\
\text { the streets }\end{array}$ & 17 & Feeling unsafe & 4.1 \\
\hline & $\begin{array}{l}\text { Being afraid that someone comes into their home or } \\
\text { something happens with their home }\end{array}$ & 27 & Being afraid & 3.1 \\
\hline & Having watched a scary movie & 30 & Watching something scary & 3.9 \\
\hline & Having watched the news & 31 & Watching something scary & 3.3 \\
\hline \multirow[t]{8}{*}{$\begin{array}{l}\text { 5. physical- and mental } \\
\text { well-being }\end{array}$} & & & & 3.7 \\
\hline & $\begin{array}{l}\text { When other children were unkind and still worrying } \\
\text { about this }\end{array}$ & 16 & Being bullied & 4.2 \\
\hline & Feeling pain & 25 & Pain & 4.2 \\
\hline & Being ill & 26 & Illness & 4.2 \\
\hline & Having had inadequate stimulation during the day & 34 & Inadequate daytime stimulation & 3.1 \\
\hline & Having had excessive stimulation during the day & 35 & Excessive daytime stimulation & 3.4 \\
\hline & $\begin{array}{l}\text { Dreams that keep children awake or wake them and } \\
\text { cause restless sleep }\end{array}$ & 36 & Unpleasant dreams & 3.3 \\
\hline & $\begin{array}{l}\text { When something happens in the light sleep phase, } \\
\text { waking the child and giving opportunity to start } \\
\text { thinking }\end{array}$ & 37 & Many thoughts & 3.0 \\
\hline \multirow[t]{3}{*}{$\begin{array}{l}\text { 6. Screen behaviour before } \\
\text { bedtime }\end{array}$} & & & & 4.1 \\
\hline & $\begin{array}{l}\text { Activating computer games that cause stress before } \\
\text { bedtime }\end{array}$ & 40 & $\begin{array}{l}\text { Play with activating toys before } \\
\text { bedtime }\end{array}$ & 4.4 \\
\hline & $\begin{array}{l}\text { The light of screens (tablet, computer) right before going } \\
\text { to sleep }{ }^{4}\end{array}$ & 41 & Screen use before bedtime & 3.7 \\
\hline
\end{tabular}

${ }^{1}$ Idea nr. = The number of the generated idea in this group. This corresponds with the numbers on the concept maps in Appendix A. ${ }^{2}$ Merged into main idea $=$ The overall main idea to which the original idea of this group is assigned. ${ }^{3}$ Mean $=$ mean importance rating on a 5-point Likert scale based on the question: 'Think about the sleep of a child in the age of 4-12 years, how much does this affect their sleep?' answered on a 5-point Likert scale from 'does not affect at all $=1^{\prime}$ to 'affects a whole lot $=5^{\prime} ;{ }^{4}$ a new cluster was created with this idea. Bold values indicate ideas rated as important (with a rating $\geq 3.00$ ); Cursive values indicate the overall mean rating per cluster. $\mathrm{S} 1=$ Session 1 , brainstorm; $\mathrm{S} 2$ = Session 2, sort and rate . 
Table A10. Cluster compositions of original ideas and mean importance ratings of parents in group 4 (S1 $N=7$; S2 $N=6$ ), including the assignment of original ideas to main ideas.

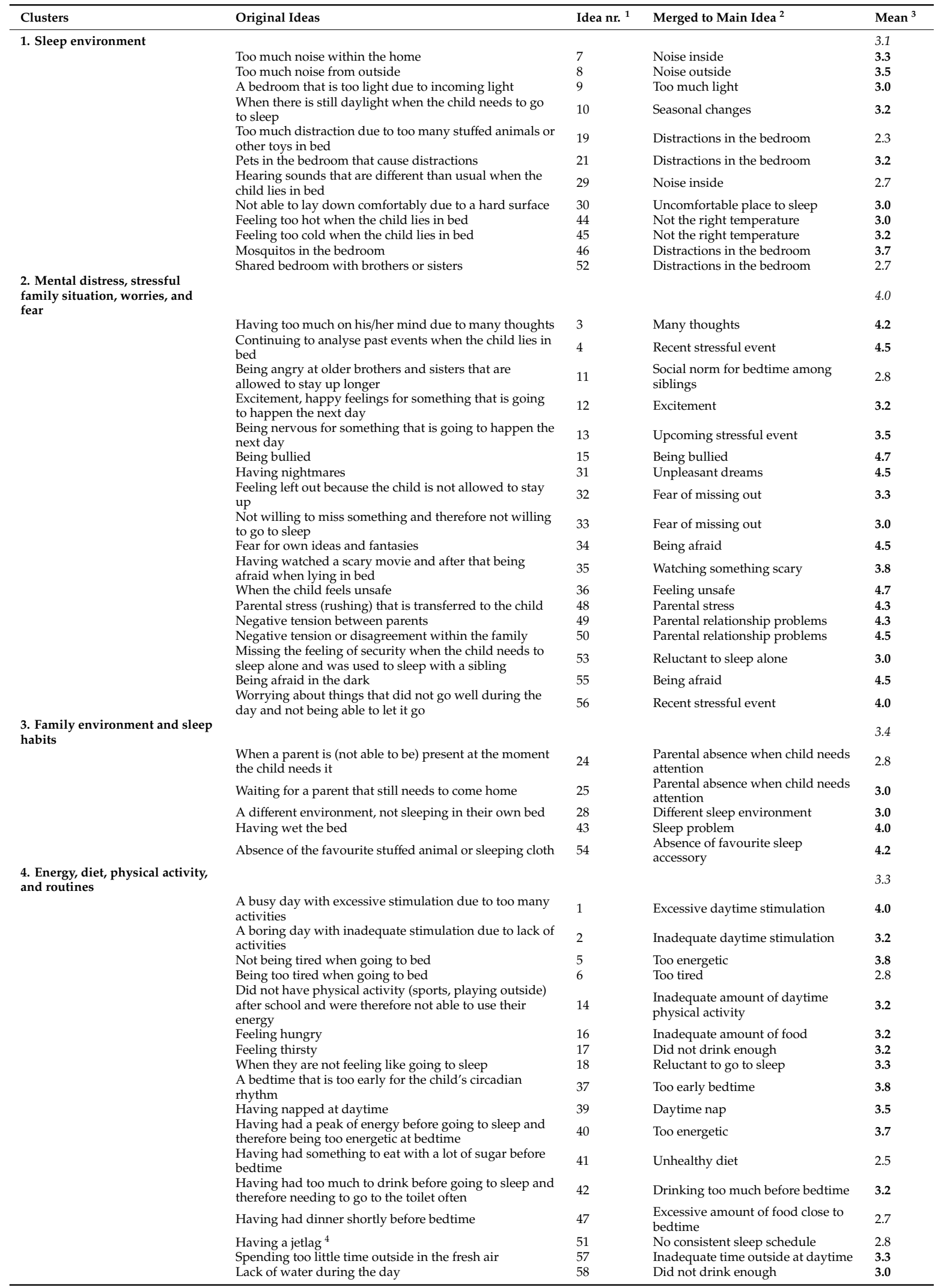


Table A10. Cluster compositions of original ideas and mean importance ratings of parents in group 4 (S1 $N=7$; $22 N=6$ ), including the assignment of original ideas to main ideas.

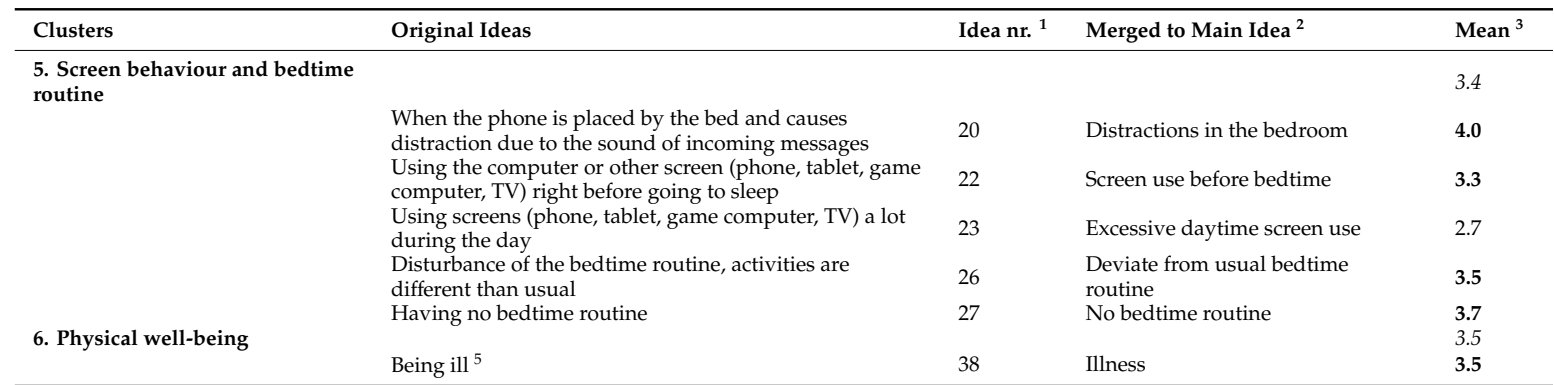

${ }^{1}$ Idea nr. $=$ The number of the generated idea in this group. This corresponds with the numbers on the concept maps in Appendix A. ${ }^{2}$ Merged into main idea = The overall main idea to which the original idea of this group is assigned. ${ }^{3}$ Mean $=$ mean importance rating on a 5-point Likert scale based on the question: "Think about the sleep of a child in the age of 4-12 years, how much does this affect their sleep?' answered on a 5-point Likert scale from 'does not affect at all $=1$ ' to 'affects a whole lot $=5^{\prime} ;{ }^{4}$ this idea was moved from cluster 5 to cluster $4 ;^{5}$ this idea was subtracted from cluster 5 . Bold values indicate ideas rated as important (with a rating $\geq 3.00$ ); Cursive values indicate the overall mean rating per cluster. $\mathrm{S} 1=$ Session 1 , brainstorm; $\mathrm{S} 2=$ Session 2 , sort and rate.

\section{References}

1. Hirshkowitz, M.; Whiton, K.; Albert, S.M.; Alessi, C.; Bruni, O.; DonCarlos, L.; Hazen, N.; Herman, J.; Adams Hillard, P.J.; Katz, E.S.; et al. National Sleep Foundation's updated sleep duration recommendations: Final report. Sleep Health 2015, 1, 233-243. [CrossRef] [PubMed]

2. Buysse, D.J. Sleep health: Can we define it? Does it matter? Sleep 2014, 37, 9-17. [CrossRef] [PubMed]

3. Astill, R.G.; Van der Heijden, K.B.; Van Ijzendoorn, M.H.; Van Someren, E.J. Sleep, cognition, and behavioral problems in school-age children: A century of research meta-analyzed. Psychol. Bull. 2012, 138, 1109-1138. [CrossRef]

4. Kopasz, M.; Loessl, B.; Hornyak, M.; Riemann, D.; Nissen, C.; Piosczyk, H.; Voderholzer, U. Sleep and memory in healthy children and adolescents-A critical review. Sleep Med. Rev. 2010, 14, 167-177. [CrossRef] [PubMed]

5. Chaput, J.P.; Gray, C.E.; Poitras, V.J.; Carson, V.; Gruber, R.; Olds, T.; Weiss, S.K.; Connor Gorber, S.; Kho, M.E.; Sampson, M.; et al. Systematic review of the relationships between sleep duration and health indicators in school-aged children and youth. Appl. Physiol. Nutr. Metab. 2016, 41, S266-S282. [CrossRef] [PubMed]

6. Dewald, J.F.; Meijer, A.M.; Oort, F.J.; Kerkhof, G.A.; Bogels, S.M. The influence of sleep quality, sleep duration and sleepiness on school performance in children and adolescents: A meta-analytic review. Sleep Med. Rev. 2010, 14, 179-189. [CrossRef]

7. Maski, K.P.; Kothare, S.V. Sleep deprivation and neurobehavioral functioning in children. Int. J. Psychophysiol. 2013, 89, 259-264. [CrossRef]

8. Fatima, Y.; Doi, S.A.; Mamun, A.A. Longitudinal impact of sleep on overweight and obesity in children and adolescents: A systematic review and bias-adjusted meta-analysis. Obes. Rev. 2015, 16, 137-149. [CrossRef]

9. Nielsen, L.S.; Danielsen, K.V.; Sorensen, T.I. Short sleep duration as a possible cause of obesity: Critical analysis of the epidemiological evidence. Obes. Rev. 2011, 12, 78-92. [CrossRef]

10. Sadeh, A.; Tikotzky, L.; Kahn, M. Sleep in infancy and childhood: Implications for emotional and behavioral difficulties in adolescence and beyond. Curr. Opin. Psychiatry 2014, 27, 453-459. [CrossRef]

11. Matricciani, L.; Bin, Y.S.; Lallukka, T.; Kronholm, E.; Dumuid, D.; Paquet, C.; Olds, T. Past, present, and future: Trends in sleep duration and implications for public health. Sleep health 2017, 3, 317-323. [CrossRef] [PubMed]

12. Singh, G.K.; Kenney, M.K. Rising Prevalence and Neighborhood, Social, and Behavioral Determinants of Sleep Problems in US Children and Adolescents, 2003-2012. Sleep Disord. 2013, 2013, 394320. [CrossRef] [PubMed]

13. Van Litsenburg, R.R.; Waumans, R.C.; van den Berg, G.; Gemke, R.J. Sleep habits and sleep disturbances in Dutch children: A population-based study. Eur. J. Pediatr. 2010, 169, 1009-1015. [CrossRef] [PubMed]

14. Jarrin, D.C.; McGrath, J.J.; Quon, E.C. Objective and subjective socioeconomic gradients exist for sleep in children and adolescents. Health Psychol. 2014, 33, 301-305. [CrossRef] [PubMed] 
15. Bartholomew, L.K.; Parcel, G.S.; Kok, G.; Gottlieb, N.H. Planning Health Promotion Programs: An Intervention Mapping Approach, 2nd ed.; Jossey-Bass: San Francisco, CA, USA, 2016; p. 765.

16. Belmon, L.S.; van Stralen, M.M.; Busch, V.; Harmsen, I.A.; Chinapaw, M.J.M. What are the determinants of children's sleep behavior? A systematic review of longitudinal studies. Sleep Med. Rev. 2019, 43, 60-70. [CrossRef]

17. Allen, S.L.; Howlett, M.D.; Coulombe, J.A.; Corkum, P.V. ABCs of SLEEPING: A review of the evidence behind pediatric sleep practice recommendations. Sleep Med. Rev. 2016, 29, 1-14. [CrossRef]

18. Kane, M.T.; Trochim, W.M.K. Concept Mapping for Planning and Evaluation; SAGE Publications: Thousand Oaks, CA, USA, 2007.

19. Hidding, L.M.; Altenburg, T.M.; van Ekris, E.; Chinapaw, M.J.M. Why Do Children Engage in Sedentary Behavior? Child- and Parent-Perceived Determinants. Int. J. Environ. Res. Public Health 2017, $14,671$. [CrossRef]

20. Hidding, L.M.; Chinapaw, M.J.M.; Altenburg, T.M. An activity-friendly environment from the adolescent perspective: A concept mapping study. Int. J. Behav. Nutr. Phys. Act. 2018, 15, 99. [CrossRef]

21. Voor de Statistiek, C.B. Standaard onderwijsindeling 2006 (The Dutch Standard Classification of Education). 2006. Available online: https://www.cbs.nl/en-gb/background/2008/24/the-dutch-standard-classification-ofeducation-soi-2006 (accessed on 20 February 2019).

22. Riley, A.W. Evidence that school-age children can self-report on their health. Ambul. Pediatr. 2004, 4, 371-376. [CrossRef]

23. Ariadne. Available online: http://www.minds21.org/ (accessed on 20 February 2019).

24. Bagley, E.J.; Kelly, R.J.; Buckhalt, J.A.; El-Sheikh, M. What keeps low-SES children from sleeping well: The role of presleep worries and sleep environment. Sleep Med. 2015, 16, 496-502. [CrossRef]

25. Peterman, J.S.; Carper, M.M.; Kendall, P.C. Anxiety disorders and comorbid sleep problems in school-aged youth: Review and future research directions. Child Psychiatry Hum. Dev. 2015, 46, 376-392. [CrossRef]

26. Stueck, M.; Gloeckner, N. Yoga for children in the mirror of the science: Working spectrum and practice fields of the training of relaxation with elements of yoga for children. Early Child. Dev. Care 2005, 175, 371-377. [CrossRef]

27. El-Sheikh, M.; Kelly, R.J. Family Functioning and Children's Sleep. Child. Dev. Perspect. 2017, 11, $264-269$. [CrossRef] [PubMed]

28. Kelly, R.J.; Marks, B.T.; El-Sheikh, M. Longitudinal Relations between Parent-Child Conflict and Children's Adjustment: The Role of Children's Sleep. J. Abnorm. Child. Psychol. 2014, 42, 1175-1185. [CrossRef]

29. Tikotzky, L. Parenting and sleep in early childhood. Curr. Opin. Psychol. 2017, 15, 118-124. [CrossRef] [PubMed]

30. Dolezal, B.A.; Neufeld, E.V.; Boland, D.M.; Martin, J.L.; Cooper, C.B. Interrelationship between Sleep and Exercise: A Systematic Review. Adv. Prev. Med. 2017, 2017, 1364387. [PubMed]

31. Chennaoui, M.; Arnal, P.J.; Sauvet, F.; Leger, D. Sleep and exercise: A reciprocal issue? Sleep Med. Rev. 2015, 20, 59-72. [CrossRef] [PubMed]

32. Harrex, H.A.L.; Skeaff, S.A.; Black, K.E.; Davison, B.K.; Haszard, J.J.; Meredith-Jones, K.; Quigg, R.; Saeedi, P.; Stoner, L.; Wong, J.E.; et al. Sleep timing is associated with diet and physical activity levels in 9-11-year-old children from Dunedin, New Zealand: The PEDALS study. J. Sleep Res. 2018, 27, e12634. [CrossRef]

33. Lin, Y.; Borghese, M.M.; Janssen, I. Bi-directional association between sleep and outdoor active play among 10-13 year olds. BMC Public Health 2018, 18, 224. [CrossRef]

34. Cordova, F.V.; Barja, S.; Brockmann, P.E. Consequences of short sleep duration on the dietary intake in children: A systematic review and metanalysis. Sleep Med. Rev. 2018, 42, 68-84. [CrossRef]

35. Peuhkuri, K.; Sihvola, N.; Korpela, R. Diet promotes sleep duration and quality. Nutr. Res. 2012, 32, 309-319. [CrossRef] [PubMed]

36. Stutz, J.; Eiholzer, R.; Spengler, C.M. Effects of Evening Exercise on Sleep in Healthy Participants: A Systematic Review and Meta-Analysis. Sports Med. 2019, 49, 269-287. [CrossRef] [PubMed]

37. Hale, L.; Guan, S. Screen time and sleep among school-aged children and adolescents: A systematic literature review. Sleep Med. Rev. 2015, 21, 50-58. [CrossRef] [PubMed] 
38. Hale, L.; Kirschen, G.W.; LeBourgeois, M.K.; Gradisar, M.; Garrison, M.M.; Montgomery-Downs, H.; Kirschen, H.; McHale, S.M.; Chang, A.M.; Buxton, O.M. Youth Screen Media Habits and Sleep: Sleep-Friendly Screen Behavior Recommendations for Clinicians, Educators, and Parents. Child Adolesc. Psychiatr. Clin. N. Am. 2018, 27, 229-245. [CrossRef] [PubMed]

39. Ash, T.; Agaronov, A.; Young, T.; Aftosmes-Tobio, A.; Davison, K.K. Family-based childhood obesity prevention interventions: A systematic review and quantitative content analysis. Int. J. Behav. Nutr. Phys. Activity 2017, 14, 113. [CrossRef]

40. Basner, M.; McGuire, S. WHO Environmental Noise Guidelines for the European Region: A Systematic Review on Environmental Noise and Effects on Sleep. Int. J. Environ. Res. Public Health 2018, 15, 519. [CrossRef]

41. Spilsbury, J.C.; Patel, S.R.; Morris, N.; Ehayaei, A.; Intille, S.S. Household chaos and sleep-disturbing behavior of family members: Results of a pilot study of African American early adolescents. Sleep Health 2017, 3, 84-89. [CrossRef]

42. Hall, L.; Hume, C.; Tazzyman, S. Five Degrees of Happiness: Effective Smiley Face Likert Scales for Evaluating with Children. In Proceedings of the 15th International Conference on Interaction Design and Children; ACM: Manchester, UK, 2016; pp. 311-321.

43. Smyth, J.M.; Stone, A.A. Ecological Momentary Assessment research in behavioral medicine. J. Happiness Stud. 2003, 4, 35-52. [CrossRef]

44. Dahlgren, G.; Whitehead, M. Policies and strategies to promote social equity in health. Stockh. Inst. Future Stud. 1991, 1-69.

45. Kok, G.; Gottlieb, N.H.; Commers, M.; Smerecnik, C. The ecological approach in health promotion programs: A decade later. Am. J. Health Promot. 2008, 22, 437-442. [CrossRef]

46. Arnold, R.D.; Wade, J.P. A Definition of Systems Thinking: A Systems Approach. Procedia Comput. Sci. 2015, 44, 669-678. [CrossRef]

47. Sonntag, D.; Sweeney, R.; Litaker, D.; Moodie, M. Economic evaluations of system-based obesity interventions-The case for a new approach. Obes. Rev. 2018, 19, 885-887. [CrossRef] [PubMed]

(C) 2020 by the authors. Licensee MDPI, Basel, Switzerland. This article is an open access article distributed under the terms and conditions of the Creative Commons Attribution (CC BY) license (http://creativecommons.org/licenses/by/4.0/). 